UNIVERSIDADE DE BRASÍLIA - UNB

FACULDADE DE CEILÂNDIA

PROGRAMA DE PÓS-GRADUAÇÃO STRICTO-SENSU

EM CIÊNCIAS E TECNOLOGIAS EM SAÚDE

MARIANNE LUCENA DA SILVA

EFEITOS DA ESTIMULAÇÃO ELÉTRICA DE BAIXA FREQUÊNCIA NO REMODELAMENTO E DESEMPENHO MUSCULAR, RESPOSTA OXIDATIVA E INFLAMATÓRIA EM PACIENTES COM INSUFICIÊNCIA CARDÍACA

BRASÍLIA-DF 


\section{EFEITOS DA ESTIMULAÇÃO ELÉTRICA DE BAIXA FREQUÊNCIA NO REMODELAMENTO E DESEMPENHO MUSCULAR, RESPOSTA OXIDATIVA E INFLAMATÓRIA EM PACIENTES COM INSUFICIÊNCIA CARDÍACA}

Tese apresentada ao Programa de Pósgraduação em Ciências e Tecnologias em Saúde, da Universidade de Brasília - UnB como requisito parcial para obtenção do título de doutor.

Orientador: Prof. Dr. Gerson Cipriano Júnior Coorientador: Prof. Dr. Eduardo A. Ferreira Orientador no exterior: Prof. Dr. José A. Neder 
Efeitos da estimulação elétrica de baixa frequência no remodelamento e desempenho muscular, resposta oxidativa e inflamatória em pacientes com insuficiência cardíaca / Marianne Lucena da Silva; orientador Gerson Cipriano Junior; co-orientador Eduardo A. Ferreira. -- Brasilia, 2017. $67 \mathrm{p}$.

Tese (Doutorado - Doutorado em Ciências e Tecnologias em Saúde) -- Universidade de Brasilia, 2017.

1. Insuficiência Cardíaca. 2. Matriz Extracelular. 3. Estresse Oxidativo. 4. Estimulação Elétrica Nervosa Transcutẩnea. 5. Inflamação. I. Cipriano Junior, Gerson, orient. II. A. Ferreira, Eduardo, co orient. III. Título. 
MEMBROS DA BANCA

Esta dissertação, intitulada "Efeitos da estimulação elétrica de baixa frequência no remodelamento e desempenho muscular, resposta oxidativa e inflamatória em pacientes com insuficiência cardíaca”, com autoria de Marianne Lucena da Silva, foi apresentada no dia 6 de março de 2017 como requisito parcial para obtenção do título de Doutor em Ciências e Tecnologias em Saúde. A banca avaliadora foi formada por:

Prof. Dr. Gerson Cipriano Jr. (presidente)

Faculdade de Ceilândia da Universidade de Brasília

Programa de Pós-Graduação em Ciências e Tecnologias em Saúde

Prof. Dr. Vinícius Zacarias Maldaner da Silva (avaliador externo)

Fundação de Ensino e Pesquisa em Ciências da Saúde

Escola Superior de Ciências da Saúde

Prof. Dr. Sérgio Ricardo Menezes Mateus (avaliador externo)

Faculdade do Gama da Universidade de Brasília

Programa da Pós-Graduação em Engenharia Biomédica

Profa. Dra. Graziella França Bernardelli Cipriano (avaliador interno)

Faculdade de Ceilândia da Universidade de Brasília

Programa de Pós-Graduação em Ciências e Tecnologias em Saúde

Prof. Dr. João Luiz Quagliotti Durigan (avaliador interno)

Faculdade de Ceilândia da Universidade de Brasília

Programa de Pós-Graduação em Ciências e Tecnologias em Saúde

Prof. Dr. Wagner Rodrigues Martins (avaliador suplente)

Universidade de Brasília

Programa de Pós-Graduação em Ciências da Reabilitação 


\section{AGRADECIMENTOS}

Eu não imaginava que esse caminho me levaria a realizar sonhos. Em três anos eu vi o laboratório de pesquisa e um programa de atendimento a pessoas com doenças cardíacas sair do papel. Dá para acreditar que temos tecnologia para desenvolver pesquisas aqui no Brasil tão boas quanto no exterior? Sim, nesse tempo tive a oportunidade de morar fora do país e aprender muito. E nesse processo de aprendizagem científica, pude amadurecer e ter mais paciência comigo mesma.

Essa caminhada não tem sido fácil. Às vezes requer uma motivação, uma força que encontro em mim mesma e nas minhas conversas com Deus. Estou longe de saber tudo, mas tenho a certeza de que cada dia tenho vontade de aprender mais e que esse conhecimento será útil. Essa caminhada ao conhecimento é sem fim.

Meus sinceros agradecimentos:

Ao meu orientador, Dr. Gerson Cipriano Jr., que há 8 anos me orienta a ser uma pesquisadora e cientista e a ser uma pessoa melhor todos os dias. Obrigada pela paciência e pela confiança.

Ao meu orientador em Kingston, Dr. José Alberto Neder, por ter sido um exemplo de profissional e ser humano, por dividir seu conhecimento e por mostrar que, seja o caminho escolhido para percorrer, que se tenha dedicação.

Aos amigos do Grupo de Pesquisa em Reabilitação Cardiopulmonar e Tecnologias Assistivas, do Grupo de Plasticidade Músculo Tendínea, do Grupo de Pesquisa em Treinamento de Força, do Grupo de pesquisa em Processamento de Sinais Biológicos e do Laboratory of Clinical Exercise Physiology, por terem fornecido suporte na idealização, coleta e análise dos dados e durante todo o processo de aprendizado ocorrido ao longo do processo de realização deste trabalho. Sem essas parcerias nada disso teria sido possível.

A Alexandra Lima e André Martorelli, meus amigos e parceiros de pesquisa, e aos alunos de iniciação científica Layse Parente, André Gerez, Lucas Marques, Ruanna Furtado e Natália Barrel, pelo apoio nas coletas e por comprar muitas brigas no dia-a-dia desta pesquisa;

Ao CNPq, à CAPES e à FEPECS pelo apoio financeiro neste projeto, e ao Instituto de Cardiologia do DF, ao Hospital das Forças Armadas e à clínica Core Cardiologia, pelo apoio diário no recrutamento dos pacientes e nas coletas de material biológico para este estudo; 
Aos pacientes, por permitirem a realização desta pesquisa em um momento de tanta incompreensão e dificuldades;

Aos meus amigos; aos meus familiares; aos meus pais, Roseane e José Ivan; e ao meu irmão, Fabiano, por partilharem cada um dos meus sonhos comigo e por compreender as ausências. A eles e por eles, minha gratidão. 
"Vivemos numa sociedade intensamente dependente de ciência e da tecnologia, em que quase ninguém sabe algo sobre a ciência e tecnologia”. Carl Sagan 


\section{RESUMO}

Introdução: A estimulação elétrica de baixa frequência (EEBF) tem sido utilizada como recurso terapêutico adjuvante no processo de reabilitação de pacientes com insuficiência cardíaca (IC). Estudos recentes têm demonstrado resultados positivos na capacidade cardiorrespiratória e força muscular nesta população. Entretanto, ainda são escassos os estudos sobre os mecanismos de atuação da EEBF por meio das respostas inflamatória e oxidativas e do remodelamento da matriz extracelular. Objetivos: Avaliar o efeito da EEBF nos biomarcadores de remodelamento muscular, inflamação e estresse oxidativo, na capacidade cardiorrespiratória e o no desempenho muscular de pacientes com IC. Métodos: Vinte e seis pacientes $(52,5 \pm 9,12$ anos e índice de massa corpórea médio de 27,09 $\pm 4,16)$ receberam aleatoriamente a EEBF (frequência: $25 \mathrm{~Hz}$, largura de pulso: 400ms, tempo de estimulação e repouso: 10s e intensidade: corrente máxima tolerada) ou EEBF sham (intensidade: 0mA) nos músculos quadríceps e gastrocnêmicos uma vez ao dia, durante 1 hora, 5 vezes na semana por 10 semanas. Resultados: Foram observadas mudanças no grupo EEBF em comparação ao sham, aumento no biomarcador de remodelamento muscular por meio da MMP-2 ( $\Delta 8,10$ vs $\Delta 0,31)$ ( $\mathrm{p}<0,024)$, redução na MMP-9 $(\Delta-0,34$ vs $\Delta+0,11)(\mathrm{p}<0,042)$, e redução da resposta próinflamatória TNF- $\alpha(-41 \%$ vs $-2 \%$ ) ( $\mathrm{p}<0,049)$. A EEBF não produziu modificação no estresse oxidativo, na capacidade cardiorrespiratória e desempenho muscular. Conclusão: A EEBF influenciou positivamente na resposta dos biomarcadores de remodelamento muscular e redução da atividade inflamatória, entretanto as respostas observadas não foram traduzidas em ganhos na capacidade cardiorrespiratória e desempenho muscular. Estes achados sugerem que a EEBF pode ser utilizada como uma alternativa de preparação ou tratamento de pacientes com IC.

Palavras-chave: Insuficiência Cardíaca; Matriz Extracelular; Estresse Oxidativo; Estimulação Elétrica Nervosa Transcutânea; Inflamação. 


\begin{abstract}
Introduction: Low-frequency electrical stimulation (LFES) was included in clinical practice as a rehabilitation method in patients with heart failure (HF); Recently, several investigations have shown that training with LFES produced positive physiological adaptations in these patients, but it is still uncertain as to its effects of inflammatory reduction and muscle remodeling. Purpose: To determine the effect of a home rehabilitation program with EEBF non-remodeling and muscle performance and the oxidative and inflammatory responses in patients with HF. Methods: Twenty-six patients with stable HF were randomly assigned into two groups. Patients in (i) group sham underwent 10 weeks of small device with 5mA intensity; and (ii) group LFES performed 10 weeks of LFES of quadriceps and calf muscle (frequency $25 \mathrm{~Hz}$, mode "10s-on 10s-off, maximal intensity tolerance), 1 x $60 \mathrm{~min}, 5$ times per week and during 10 weeks. RESULTS: Changes in the LFES group were observed when compared to the sham group. There was an increase in the muscle remodeling biomarker through the MMP$2(\Delta 8,10$ vs $\Delta 0,31)(\mathrm{p}<0,049)$, a decrease in the MMP-9 $(\Delta-0,34$ vs $\Delta+0,11)(\mathrm{p}<0,042)$, and also a decrease in the TNF- $\alpha$ proinflammatory responde(- $41 \%$ vs $-2 \%)$ (p < 0,0642). The markers of oxidative stress, cardiorespiratory capacity, muscle strength and muscle activation unchanged. Conclusion: LFES has been shown to improve significantly remodeling muscle and reduced inflammatory variables. These results suggest that the use of LFES is an adjuvant method for rehabilitation and may prevent damage muscle in patients with HF.
\end{abstract}

Key-words: Heart Failure, Matrix metalloproteinases, Oxidative Stress, Electrical stimulation; Inflammation. 


\section{LISTA DE ILUSTRAÇÕES}

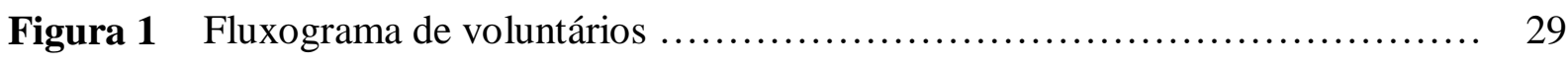

Figura 2 Ilustração do experimento ....................................... 30

Figura 3 Realização do teste de esforço cardiopulmonar com coleta de variáveis ventilatórias pelo uso de peça bocal .................................... 33

Figura 4 Avaliação da força isométrica dos extensores de joelho no dinamômetro isocinético.......................................................... 34

Figura 5 Ilustrações do posicionamento dos eletrodos de EMG em músculo vasto medial

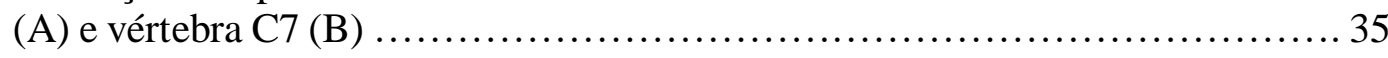

Figura 6 Sinal de eletromiografia de torque isométrico do reto femoral e vasto medial ....... 36

Figura 7 Ilustrações da colocação dos eletrodos da eletroestimulação nas musculaturas vasto medial (A), reto femoral (A), e cabeça proximal do gastrocnêmico (B) ....... 38 


\section{LISTA DE TABELAS}

Tabela 1 Características clínicas, epidemiológicas e funcionais dos pacientes com IC submetidos a eletroestimulação

Tabela 2 Níveis de concentração de citocinas no plasma pré e pós treinamento nos grupos sham e EEBF

Tabela 3 Níveis de concentração no plasma de estresse oxidativo nos grupos sham e eletroestimulação

Tabela 4 Variáveis de capacidade cardiorrespiratória nos grupos sham e eletroestimulação

Tabela 5 Variáveis de desempenho muscular pré e pós treinamento nos grupos sham e EEBF 


\section{LISTA DE GRÁFICOS}

Gráfico 1 Comparativo de níveis de concentração plasmático da metaloproteinase -2 pré e pós treinamento nos grupos sham e EEBF .

Gráfico 2 Comparativo de níveis de concentração plasmático da metaloproteinase -9 pré e pós treinamento nos grupos sham e EEBF

Gráfico 3 Comparativo de níveis de concentração plasmático do fator de necrose tumoral pré e pós treinamento nos grupos sham e EEBF 


\section{LISTA DE ABREVIAÇÕES E SIGLAS}

IC Insuficiência cardíaca

IL Interleucina

MMP's Metaloproteinase da matriz

FRAP Poder antioxidante reduzido férrico

TBARS Substâncias reativas ao ácido tiobarbitúrico

iSON Indução da sintetase do óxido nítrico

PT Pico de Torque

TECP Teste de exercício cardiopulmonar

BNP Peptídeo natriurético cerebral

EEBF Estimulação elétrica de baixa frequência

NYHA New York Heart Association

UnB Universidade de Brasília

IC-DF Instituto de Cardiologia do Distrito Federal

DICOM Digital Imaging and Communication in Medicine

EMGs Eletromiografia de superfície

SENIAM Surface Electromyography for the Non-Invasive Assessment of Muscles

RMS Média da raiz quadrada

CIVM Contração isométrica voluntária máxima

TDF Taxa de desenvolvimento de força

EVA Escala visual analógica de dor 


\section{LISTA DE SÍMBOLOS}

$\grave{\mathrm{V}}_{2} \quad$ Consumo de oxigênio no pico do exercício

$\mathrm{VO}_{2}$ LA Consumo de oxigênio no limiar anaeróbico

VE Volume minuto

$\mathrm{VCO}_{2}$ Produção de gás carbônico

$\mathrm{Hz} \quad$ Hertz

$\mathrm{Pg} / \mathrm{mL} \quad$ Picograma por mililitro

$\mu \mathrm{mol} / \mathrm{L} \quad$ Micromoles / litro

UA Unidade arbitrária

Ma Miliamperes

$\mathrm{Db} \quad$ Decibel

$\mathrm{O}_{2} \quad$ Oxigênio

$\mathrm{CO}_{2} \quad$ Gás carbônico 


\section{SUMÁRIO}

1 INTRODUÇÃ

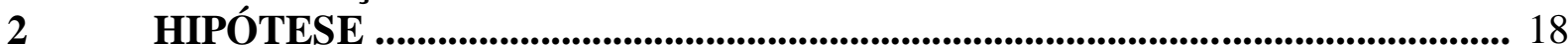

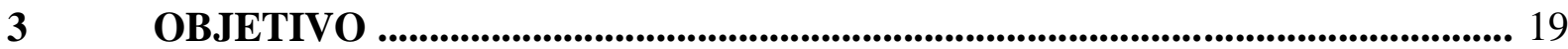

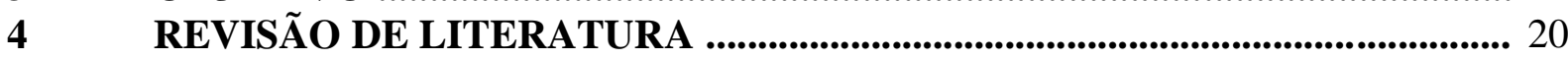

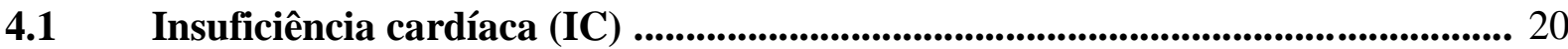

4.2 Remodelamento muscular ................................................................................. 21

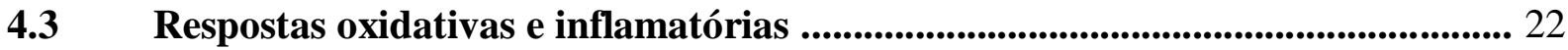

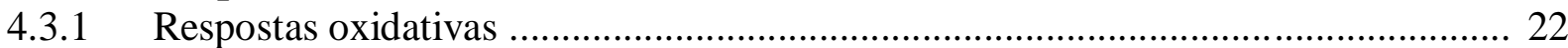

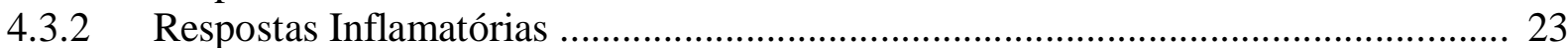

4.4 Desempenho muscular ............................................................................................... 25

4.5 Capacidade Cardiopulmonar ....................................................................................... 26

4.6 Estimulação elétrica de Baixa Frequência (EEBF) ................................................... 27

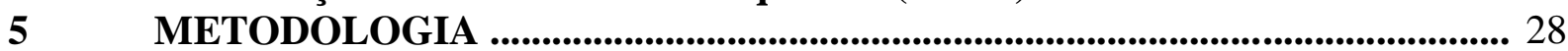

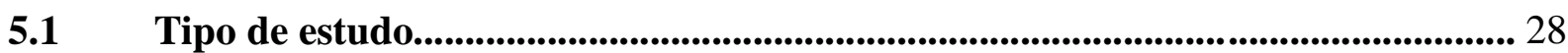

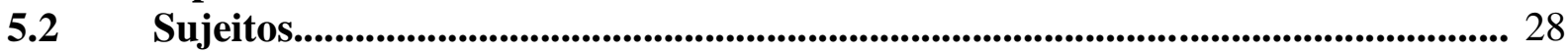

5.3 Desenho Experimental............................................................................................................ 30

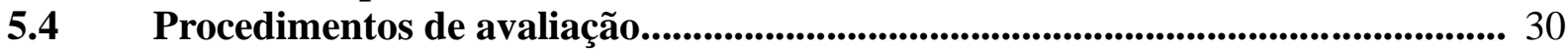

5.4.1 Avaliação da função cardíaca ........................................................................... 30

5.4.2 Avaliação de biomarcadores de remodelamento muscular, inflamatórios e estresse

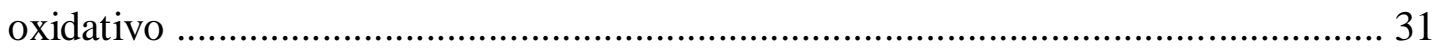

5.4.3 Avaliação da capacidade cardiopulmonar ............................................................... 32

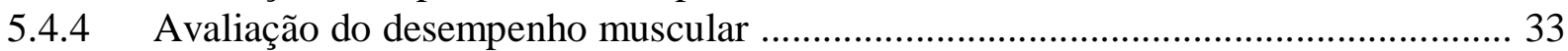

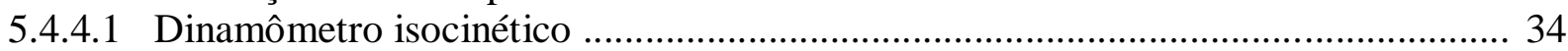

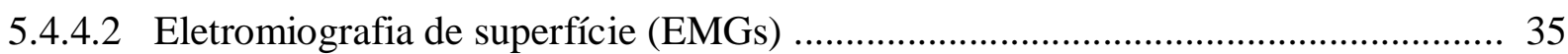

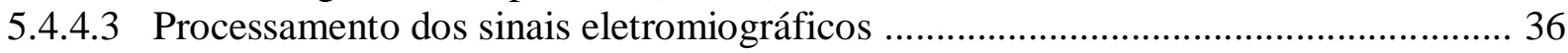

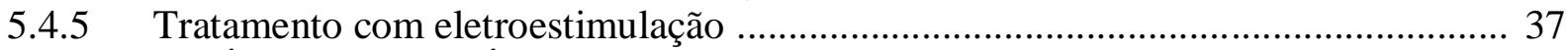

6 ANÁLISE ESTATÍSTICA _.................................................................................... 38

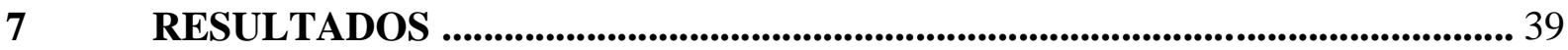

8 DISCUSSÃO

9 CONCLUSÃO E CONSIDERAÇÕES FINAIS ..................................................... 50

REFERÊNCIAS ........................................................................................................... 51

APÊNDICE A - Termo de Consentimento Livre e Esclarecido .............................. 62

APÊNDICE B - ficha de identificação da amostra .................................................. 63

APÊNDICE C - Contribuições científicas durante o doutorado ............................... 66

ANEXO A - Termo de aprovação do comitê de ética e pesquisa ............................. 67 


\section{INTRODUÇÃO}

A insuficiência cardíaca (IC) é uma síndrome clínica complexa ${ }^{1,2}$, definida como uma disfunção ${ }^{3}$ que envolve distúrbios vasculares, hemodinâmicos, neuro-humorais e periféricos ${ }^{4}$. Tem sido relacionada a altas concentrações de radicais livres e aumento da atividade simpática e inflamatória ${ }^{5}$, disfunções diretamente relacionadas ao nível de remodelamento cardíaco ${ }^{6}$ e à perda de massa muscular esquelética ${ }^{7}$. Sua fisiopatologia é desencadeada por processos metabólicos distintos, mas que interagem entre si, favorecendo a progressão da doença nesta população.

As disfunções musculares induzidas pela doença cardiovascular ${ }^{8,9}$ ocorrem pelo aumento da degradação de proteínas, da circulação de citocinas pró-inflamatórias e pelo estresse oxidativo, acarretando uma diminuição na densidade mitocondrial. Esta pode resultar em uma redução na quantidade de fibras tipo I (resistentes a fadiga), alterando sua proporção em relação às fibras do tipo II (fadigabilidade mais rápida), ocasionando intensa redução da capacidade de antioxidantes nos músculos e um aumento da tendência à fadiga precoce durante a realização de esforço físico, ${ }^{10}$ prejudicando a capacidade funcional do indivíduo ${ }^{8-10}$.

Essas alterações estão relacionadas a uma perda progressiva da força muscular e da capacidade cardiorrespiratória, as quais estão diretamente relacionadas à mortalidade nessa população ${ }^{11,12}$. Estratégias capazes de minimizar e/ou alterar o curso natural dessa perda têm sido consideradas de extrema relevância, uma vez que estão diretamente relacionadas ao prognóstico nessa população.

O tratamento baseado em exercício, incluindo treinamento aeróbico e resistido têm sido recomendado como estratégia de reabilitação e manutenção da capacidade funcional de pacientes com IC, por promover aumento no consumo de oxigênio, ganhos de força ${ }^{13,14} \mathrm{e}$ ativação muscular ${ }^{15-17}$, remodelamento vascular ${ }^{18}$, redução local das citocinas (TNF- $\alpha^{19}$, IL-1beta $^{20}$, IL- $\left.6^{19}\right)^{21,22}$, diminuição da atividade da isoforma sintase do óxido nítrico induzida $(\mathrm{SONi})^{19,22,23}$ e do dano oxidativo ${ }^{23}$, com efeito superior àqueles produzidos pela eletroestimulação elétrica de baixa frequência (EEBF)

Cabe ressaltar, no entanto, que a maior parte dos pacientes apresenta dificuldade de acesso à programas de exercício considerando o reduzido quantitativo de centros disponíveis bem como as limitações de deslocamento. Nestes casos a EEBF surge como opção terapêutica de baixo custo e fácil aplicação ${ }^{24}$ com capacidade para produzir diversos efeitos favoráveis incluindo aumento força muscular ${ }^{25}$, aumento do $\mathrm{VO}_{2 \text { pico }}{ }^{26-29}$, maior desempenho no teste de 
caminhada de seis minutos ${ }^{29}$, maior ativação simpática muscular e melhora da tolerância ao exercício $^{28-30}$, especialmente naqueles com pior Classe Funcional ${ }^{25,27,31,32}$.

Apesar de estudos indicarem a EEBF como um método de tratamento adjuvante para aprimoramento da capacidade cardiorrespiratória e muscular, existem poucos estudos que esclareçam os mecanismos fisiológicos desencadeados frente à sua aplicação ${ }^{25,33}$. Nuhr et al observaram aumentos significativos na atividade da citrato sintase, um marcador mitocondrial concomitante a uma diminuição da gliceraldeído 3-fosfato desidrogenase (GAPDH), uma enzima criadora de glicólise anaeróbia, após aplicação da EEBF por 10 semanas em pacientes com IC grave ${ }^{32}$. Os autores inferem que esse mecanismo pode alterar a produção de oxidantes, causando menos dano muscular, entretanto o estresse oxidativo não foi avaliado frente a aplicação da EEBF. Já Karavidas et al verificaram melhora da vasodilatação periférica e diminuição da atividade inflamatória, por meio de redução do fator de necrose tumoral (TNF$\alpha$ ) em um programa de EEBF realizado por 6 semanas em pacientes com IC. Em seu estudo, Karavidas sugere que a resposta observada pelo comportamento das citocinas poderia estar relacionada ao aumento da liberação do óxido nítrico, que não foi avaliada, o que justificaria o aumento observado da velocidade fluxo-mediada ${ }^{34}$. Dobsak et al também observou uma aumento da vasodilatação pela redução da big-endothelin (bet-1) no plasma e redução inflamatória pela diminuição dos níveis de creatina fosfoquinase (CPK) após 12 semanas $^{35}$.

As mudanças na matriz extra celular avaliadas pelos níveis de concentração das metalloproteinases (MMPs) desempenham uma variedade de funções homeostáticas, incluindo o remodelamento muscular e óssea, e inflamação ${ }^{36}$. As MMP-2 e MMP-9 estão relacionadas ao processo de crescimento, desenvolvimento e reparação do tecido muscular ${ }^{37,38}$. O aumento da MMP-9 foi descrito como marcador prognóstico em pacientes com insuficiência cardíaca. Além disso, Kadaglou et al e Niessner et al, verificaram que um programa crônico de exercício foi capaz de produzir adaptações musculares, que puderam ser observadas pela redução do processo inflamatório da matriz em diabéticos e em pacientes com fatores de risco para desenvolvimento de isquemia cardíaca ${ }^{40,41}$. Quanto a eletroestimulação, até o momento, foram encontrados apenas estudos que avaliaram de forma experimental, com ratos, que esta intervenção foi capaz de aumentar os níveis de MMP-2, mas não observaram essa influência sob a MMP-9 ${ }^{42,43}$.

O melhor entendimento dos mecanismos fisiológicos advindos do tratamento baseado em EEBF em pacientes com IC pode fornecer informações importantes quanto aos benefícios adicionais a essa população, que possuem importante limitação funcional e alterações fisiológicas sistêmicas. Desta forma, o objetivo do presente estudo foi avaliar o efeito 
de um programa de EEBF nos biomarcadores de remodelamento muscular, inflamação e estresse oxidativo, na capacidade cardiopulmonar e no desempenho muscular de pacientes com IC. 


\section{HIPÓTESE}

A hipótese do estudo é que a EEBF pode estimular o remodelamento muscular, diminuir a atividade inflamatória e aumentar a capacidade de antioxidantes. 


\section{OBJETIVO}

Avaliar o efeito de um programa de EEBF sobre os biomarcadores de remodelamento da matriz extracelular, inflamação e respostas oxidativas, a capacidade cardiopulmonar e o desempenho muscular de pacientes com IC. 


\section{REVISÃO DE LITERATURA}

\subsection{Insuficiência cardíaca (IC)}

A IC tem sido considerada uma epidemia e um problema de saúde pública, ${ }^{44} \mathrm{com}$ elevada taxa de mortalidade e morbidade ${ }^{45}$, que está presente em indivíduos com mais de 20 anos e foi a principal causa de morte em homens com menos de 85 anos nos Estados Unidos em $2011^{46}$. No Brasil, no ano de 2012, houve 26.694 óbitos por IC e 1.137 .572 internações por doenças do aparelho circulatório ${ }^{47}$. Os dados sobre a sobrevida e suas consequências quanto aos custos de tratamento para o paciente com IC são incontestáveis em todo o mundo ${ }^{45,48}$.

A IC caracteriza-se por redução do débito cardíaco, aumento da pressão venosa e deterioração das fibras cardíacas. A função cardíaca pode ser comprometida pela redução da fração de ejeção, pela diminuição do inotropismo no miocárdio, pela debilidade do transporte de sangue para o coração e pelo comprometimento do enchimento ou esvaziamento ventricular $^{8,49}$. Como mecanismo compensatório para atenuar a disfunção no bombeamento de sangue, ocorre uma reação hemodinâmica de defesa que visa estimular mais o coração e aumentar a perfusão de sangue para áreas mais nobres. Esta reação hemodinâmica é mediada por uma resposta inflamatória na qual mediadores pró-inflamatórios e radicais livres reagem no sistema circulatório contra agentes estranhos ${ }^{50}$; e uma resposta de remodelagem da parede do miocárdico com alterações da estrutura de câmaras ventriculares ${ }^{8,51}$.

A hipótese para a debilidade do sistema cardiovascular na IC é que há uma redução inicial da função ventricular esquerda, que ativa o catabolismo e reduz os fatores do anabolismo, ocorrendo a miopatia esquelética ${ }^{52}$. Este, por sua vez, leva à intolerância ao exercício e à consequente ativação simpática que, associada aos efeitos do catabolismo persistente, piora a estrutura e função musculoesquelética ${ }^{52}$ e dessa forma ocorre a remodelação progressiva do ventrículo esquerdo ${ }^{51}$.

A classificação funcional (CF) da IC é baseada na intensidade de sintomas em quatro classes propostas pela New York Heart Association (NYHA) ${ }^{53}$ e estratifica o grau de limitação imposta pela doença para as atividades cotidianas do indivíduo. Portanto, essa classificação, além de possuir caráter funcional, é também uma maneira de avaliar a qualidade de vida do paciente frente a sua doença. As quatro classes propostas são: CF I - ausência de sintomas (dispnéia) durante atividades cotidianas. A limitação para esforços é semelhante à esperada em indivíduos normais; CF II - sintomas desencadeados por atividades cotidianas; CF 
III - sintomas desencadeados em atividades menos intensas que as cotidianas ou pequenos esforços; CF IV - sintomas em repouso ${ }^{53,54}$.

A compreensão fisiopatológica sobre a IC no repouso e com programas de treinamento tem sido alvo de pesquisas, a fim de melhor identificar o comportamento fisiológico e aplicar com segurança os programas de reabilitação cardíaca no processo de prevenção, recuperação e reabilitação da população com cardiopatia.

\subsection{Remodelamento muscular}

A IC é caracterizada por intensa resposta inflamatória, com destruição de fibras cardíacas no foco inflamatório, levando ao aparecimento de fibrose no miocárdio, resultando em mudanças na matriz extracelular (MEC) ${ }^{55}$. A MEC é responsável pela integridade estrutural do coração e é composta por elementos estruturais, como o colágeno, e outras proteínas da matriz celular ${ }^{56}$.

Os processos de degradação e síntese da MEC são controlados por um conjunto de enzimas proteolíticas endógenas ${ }^{38}$, conhecidas como metaloproteinases de matriz (MMPs) e respondem a fatores de crescimento e citocinas, incluindo IL- $1 \beta^{57}$, TGF- $\beta^{58}$ e TNF- $\alpha^{59}$. As MMPs são uma família que inclui cerca de 25 espécies de proteases, que são essenciais para degradação do colágeno tipo IV, remodelamento vascular, angiogênese, inflamação e ruptura da placa aterosclerótica e estão envolvidas em diversas doenças, como o câncer e doenças inflamatórias e cardiovasculares ${ }^{56}$. MMPs específicas expressam-se em células cardíacas como os miócitos, fibroblastos, células endoteliais, células musculares lisas e macrófagos. Essas enzimas são sintetizadas como pró-enzimas inativas (zimógeno) e são secretadas dentro da matriz extracelular, que permanecem sem ativação até que o domínio pró-peptídico seja dividido $^{38}$.

Dentre as MMPs, destacam-se as gelatinases MMP-2 e MMP-9, que já foram descritas por participarem de alterações cardíacas ${ }^{51,55,56,60}$. Além das MMPs, seus inibidores teciduais (TIMPs) também estão envolvidos na patogênese de algumas doenças, uma vez que um desequilíbrio entre a enzima e o inibidor origina processos patológicos envolvendo a deposição da MEC, o remodelamento tecidual e a inflamação ${ }^{61}$. As células da imunidade inata, especialmente os neutrófilos e monócitos, desempenham uma função importante durante a fase aguda da doença. Na fase crônica, são importantes iniciadores e efetores da resposta imune adaptativa e ainda participam do processo inflamatório e do remodelamento cardíaco, por meio 
da produção de citocinas, e expressam os processos funcionais e patológicos de recuperação ou lesão do músculo esquelético ${ }^{62}$.

A MMP-2 é expressa constitutivamente na superfície celular e clinicamente reflete o remodelamento muscular ${ }^{63}$, enquanto que a MMP-9 é armazenada em grânulos secretórios e é induzível por estímulos endógenos ou exógenos, como por exemplo alteração de níveis de concentração de citocinas que, quando influenciam a célula-matriz, correspondem à resposta inflamatória e também participam do processo de remodelamento ${ }^{51}$.

\subsection{Respostas oxidativas e inflamatórias}

\subsubsection{Respostas oxidativas}

$\mathrm{Na}$ IC os altos níveis de estresse oxidativo estão associados à hipoperfusão periférica e consequente diminuição do débito cardíaco e disfunção endotelial periférica ${ }^{64}$. A associação de fatores como genética, idade, HAS, dislipidemias e diabetes, aumenta e predispõe o risco de aterosclerose e consequentemente predispõe a uma maior produção de radicais livres, o que induz à maior expressão de citocinas inflamatórias ${ }^{65}$ e à diminuição da capacidade antioxidante $23,66,67$.

O estresse oxidativo ocorre por um desequilíbrio entre a produção de radicais livres e as defesas antioxidantes do organismo. Um radical livre é um átomo ou molécula altamente reativo, que contém número ímpar de elétrons em sua última camada eletrônica ${ }^{64}$. Os radicais são produzidos normalmente pelo nosso organismo mediante processos metabólicos oxidativos e são úteis em diversas situações, como na produção de óxido nítrico (substância que promove o relaxamento dos vasos sanguíneos), na desintoxicação de drogas e no sistema imune. Essas substâncias são oxidantes potentes e podem causar sérios danos aos tecidos ${ }^{68}$.

Os antioxidantes são substâncias que retardam, impedem ou removem os processos de estresse oxidativo, tanto no músculo esquelético como nos demais órgãos e tecidos corporais, ou mediante antioxidantes endógenos, ou de exógenos provenientes da dieta ${ }^{64}$. Essa capacidade antioxidante depende não apenas do papel específico de cada um dos mecanismos antioxidantes, enzimáticos e não enzimáticos, como também da cooperação entre eles. Como resultado do exercício físico agudo, as taxas de produção de espécies de oxigênio aumentam, assim como o dano muscular, causado por estes mesmos compostos, e aparecimento da dor 68,69 . 
Sendo assim, na IC a capacidade total de redução do Ferro (FRAP) está reduzida e é responsável por avaliar a capacidade de defesa antioxidante do plasma, aumentando os níveis de $\mathrm{Fe}^{+3}$ a $\mathrm{Fe}^{+2}$, elevando assim o estresse e a inflamação ocasionados nas células sanguíneas ${ }^{66,70}$. Essa diminuição de capacidade antioxidante promove aumento das substâncias reativas ao ácido tiobarbitúrico (TBARS), formadas como subgrupo da peroxidação lipídica (degradação de gordura), ocorrendo lesões oxidativas ${ }^{71}$.

O Óxido Nítrico $(\mathrm{ON})$, que é um gás incolor, pouco estável na presença de $\mathrm{O}_{2}$, é responsável pelos principais processos inflamatórios, e é por isso que na IC o ON pode estar em níveis elevados ou diminuídos ${ }^{72}$. O ON é sintetizado pelo aminoácido L-arginina pela ação da enzima óxido nítrico sintetase (NOS). Suas isoformas são NOS1 (neuronal), NOS2 (induzida) e NOS3 (endotelial). A indução da sintetase do óxido nítrico (iSON) pela conversão do nitrato em nitrito é a forma indireta, avaliada por meio do sangue, induzindo o relaxamento muscular liso, devido à diminuição da concentração de cálcio $\left(\mathrm{Ca}^{2+}\right)$ e, consequentemente, ocasionando vasodilatação ${ }^{73}$.

\subsubsection{Respostas Inflamatórias}

$\mathrm{Na}$ fisiopatologia da IC, as respostas inflamatórias podem ser observadas por um aumento de concentração das citocinas, tais como o fator de necrose tumoral alfa (TNF- $\alpha$ ) e interleucina 6 (IL-6), identificados como biomarcadores prognósticos de progressão da $\mathrm{IC}^{74}$. Além disso, as citocinas atuam como fatores catabólicos envolvidos na patogênese do desgaste muscular em várias doenças, como IC ${ }^{75}$. O aumento do TNF- $\alpha$ e da IL-6 séricos está associado à redução da área do músculo esquelético e da força muscular em pacientes com $\mathrm{IC}^{76}$, bem como à diminuição do processo de remodelamento pelas MMPs ${ }^{77}$.

As interleucinas (IL), também denominadas citocinas, são tipos de proteínas produzidos principalmente por leucócitos (principalmente por linfócitos $\mathrm{T}$, macrófagos e eosinófilos), cada uma com suas funções, sendo que a maioria delas está envolvida na ativação ou supressão do sistema imune e na indução de divisão de outras células ${ }^{78}$.

Dentre as citocinas de caráter pró-inflamatório, relacionadas principalmente à defesa mediada por fagocitose contra agentes infecciosos intracelulares, a interleucina 1 (IL-1), a interleucina 6 (IL-6) e o fator de necrose tumoral (TNF- $\alpha$ ) podem ser enumeradas como as de maior destaque. Além disso, a interleucina-2 (IL-2) e o interferon- $\gamma$ (INF- $\gamma$ ), também relacionados às funções de resposta imunológica e proliferação celular ${ }^{79}$. 
O Fator de Necrose Tumoral (TNF- $\alpha$ ) é uma importante citocina, provoca catabolismo muscular mediante a resistência à insulina ${ }^{80} \mathrm{e}$ está relacionado à caquexia cardíaca, bem como aos aumentos de diversas isoformas de Interleucinas (IL-1, IL-2 e IL-6), do fator de transformação do crescimento beta (TGF- $\beta$ ), à permeabilidade vascular, ativação de monócitos e neutrófilos e à destruição direta de células infectadas ${ }^{76,78}$.

O Interferon-gama (INF $\gamma$ ) é produzido principalmente por linfócitos T, B e NK e ativado por macrófagos ou antígenos. Sua principal atividade é a imunorregulação e a indução à produção de IL-2. Tem sido associado ao aumento da expressão de antígenos de histocompatibilidade classe II em células que normalmente não os produzem, levando a doenças autoimunes ${ }^{78}$.

A Interleucina-2 (IL-2) é uma proteína que regula as atividades das células brancas do sangue (leucócitos, frequentemente linfócitos), que agem na mesma célula que está sendo secretada e são responsáveis pela imunidade. É produzida principalmente por células $\mathrm{T}$ ativadas, principalmente $\mathrm{CD} 4+$, sendo sintetizada em menor quantidade por células B e monócitos, sendo resposta natural do organismo a infecções microbianas ${ }^{78}$.

A interleucina 6 (IL-6) pode participar da estabilização da placa aterosclerótica e induz reação de fase aguda, hematopoiese, diferenciação celular e inflamação. Apresenta-se em níveis elevados nos indivíduos com IC e nas estratégias de terapias de reabilitação. As respostas agudas ao exercício têm sido associadas ao aumento dessas citocinas ${ }^{21}$.

Dentre as citocinas anti-inflamatórias, temos a interleucina 4 (IL-4) e a interleucina 10 (IL-10), relacionadas à produção de anticorpos $\operatorname{IgE}$ e a reações imunes mediadas por eosinófilos e mastócitos contra alergênicos ${ }^{81}$.

A IL-4 estimula a expressão de proteínas de adesão para que linfócitos penetrem no local da infecção. A IL- 10, quando apresenta uma diminuição na concentração plasmática em pacientes com IC, sugere uma correlação entre a melhora na tolerância ao exercício e a atenuação do processo inflamatório ${ }^{41,82}$. A IL-10 inibe a produção de INF $\gamma$, TNF- $\alpha$, IL-1, IL2 e IL-6 ${ }^{83}$. 


\subsection{Desempenho muscular}

A associação entre a IC e a redução da capacidade funcional, tanto do miocárdio quanto da musculatura esquelética de extremidade inferior, está bem estabelecida na literatura. As alterações musculares esqueléticas na IC incluem aumento na proporção de fibras musculares tipo II (contração rápida) e disfunção mitocondrial, levando à intolerância ao exercício e à baixa resistência e a desequilíbrios entre a síntese proteica e a degradação, que provocam baixa massa muscular e baixa força muscular ${ }^{10}$.

A redução da capacidade funcional está inversamente correlacionada à gravidade da IC e está diretamente relacionada ao prognóstico e à expectativa de vida ${ }^{84,85}$. Da mesma forma, a massa e a força do músculo esquelético estão relacionadas aos principais desfechos funcionais e clínicos: a força muscular das extremidades inferiores prevê a sobrevida em longo prazo na IC ${ }^{86}$,

O padrão-ouro para avaliar a força muscular é o dinamômetro isocinético computadorizado, no qual a força é quantificada enquanto a velocidade angular é controlada através de microprocessador a velocidades definidas pelo utilizador (por exemplo, isométrica, $60^{\circ} / \mathrm{s}, 180^{\circ} / \mathrm{seg}$, etc. $)^{7,87}$. Além da força, medida com o torque, a taxa de desenvolvimento de força $(\mathrm{TDF})^{88}$ e a ativação muscular ${ }^{15-17}$ são parâmetros que nos direcionam de forma indireta à fadiga precoce no indivíduo com a IC .

O Pico de Torque (PT) representa o mais alto valor na curva de torque e depende da posição e velocidade angular, medidas em Newton-metro $(\mathrm{Nm})^{89}$. A TDF é a taxa de aumento da força em um dado intervalo de tempo no início da contração muscular, que relaciona a força à velocidade de contração muscular. Os valores máximos dessa taxa, alcançados em um período de tempo, entre 100 e $300 \mathrm{~ms}^{90}$, e a eletromiografia de superfície (EMGs) identifica a fadiga do músculo esquelético pelos valores de retificação integrada da raiz da média dos quadrados (RMS) registrada durante uma contração isométrica de força constante ${ }^{15}$.

O perfil de desempenho muscular dessa população com IC mostra diminuição no pico de torque e aumento dos valores da $\mathrm{RMS}^{18}$, e consequentemente, diminuição da TDF. 


\subsection{Capacidade Cardiopulmonar}

Há vários estudos que avaliam o pico de consumo de oxigênio $\left(\mathrm{VO}_{2 \text { pico}}\right)$, a inclinação da razão de ventilação por minuto e a produção de dióxido de carbono $\left(\mathrm{VE} / \mathrm{VCO}_{2}\right)$ como variáveis importantes no diagnóstico ${ }^{91}$ e prognóstico ${ }^{92}$ de IC.

$\mathrm{VO}_{2}$ pico é reconhecido como um importante marcador prognóstico com base na sua relação com a função ventricular (capacidade de bombeamento), função vascular (fornecimento de $\mathrm{O}_{2}$ ) e capacidade metabólica do músculo esquelético (utilização de $\left.\mathrm{O}_{2}\right)^{93}$.

$\mathrm{O}$ consumo de oxigênio $\left(\mathrm{VO}_{2}\right)$ constitui o volume de $\mathrm{O}_{2}$ necessário para realizar um exercício e é extraído do ar inspirado pela ventilação pulmonar num dado período de tempo: calculado, portanto, como a diferença entre o volume de $\mathrm{O}_{2}$ inspirado e expirado e geralmente expresso em $\mathrm{ml} / \mathrm{min}$ ou $\mathrm{L} / \mathrm{min}$. Quando há um aumento linear do $\mathrm{VO}_{2}$ e incremental do trabalho muscular, denomina-se consumo de oxigênio máximo ( $\mathrm{VO}_{2}$ máx.), que apresenta uma tendência a se estabilizar, com o aumento da carga de exercício ${ }^{94}$.

Como um índice de eficiência ventilatória, a inclinação $\mathrm{VE} / \mathrm{VCO}_{2}$ mostrou refletir um desequilibro entre ventilação/perfusão nos pulmões relacionado, em parte, a uma resposta prejudicada do débito cardíaco ao exercício, ao acúmulo precoce de lactato e a anormalidades no controle respiratório. A inclinação $\mathrm{VE} / \mathrm{VCO}_{2}$ emergiu como uma variável de teste de exercício cardiopulmonar (TECP), demonstrando que, entre os pacientes com IC, ele possui valor diagnóstico ${ }^{91}$ e é um marcador prognóstico robusto ${ }^{92}$.

A taxa de incremento da relação entre a resposta ventilatória no exercício (volume minuto ou VE) e a produção de gás carbônico $\left(\mathrm{VCO}_{2}\right)$, expressos em $\mathrm{L} / \mathrm{min}$, é analisada pelo método $V$-slope $\left(\mathrm{VE} / \mathrm{VCO}_{2} \text { slope }\right)^{95}$. $\mathrm{O} \mathrm{VCO}_{2}$ produzido pelo organismo durante o exercício é gerado, em parte, a partir do metabolismo oxidativo, e outra parte resulta do tamponamento do lactato, que ocorre em níveis mais elevados de exercício, e o aumento desproporcional tanto do VE quanto do $\mathrm{VCO}_{2}$ aumenta os níveis de ácido lático, causando debilidade na função muscular esquelética ${ }^{96}$. 


\subsection{Estimulação elétrica de Baixa Frequência (EEBF)}

A EEBF é utilizada como instrumento adjuvante à reabilitação cardíaca convencional, indicado para pacientes incapazes de fazer exercício físico, ${ }^{97}$ e é de fácil uso sendo possível ao paciente utilizá-lo em ambulatório, hospitais e em domicílio ${ }^{98}$, aumentando a adesão ao tratamento ${ }^{99}$, portanto é importante na prática clínica, pela sua segurança.

Estudos que avaliam o efeito da EEBF mostram resultados positivos quanto à melhora de $\mathrm{VO}_{2}{ }^{26,28,29,100}$ e aos questionários de qualidade de vida ${ }^{97}$, ao aumento na distância no teste de caminhada de 6 minutos $^{97}$, ao desenvolvimento da força muscular periférica ${ }^{33,101-}$

104 e à modulação nas respostas endoteliais ${ }^{34,97,99,105,106}$ e nas respostas inflamatórias ${ }^{34,35}$ na população com IC.

A eletroestimulação tem algumas variáveis de ajuste, isto é, a duração do pulso, a frequência de pulso e a intensidade influenciam as fibras musculares recrutadas ou o recrutamento de unidades motoras. Estudos prévios, utilizados em uma ampla gama de pulsos simétricos bifásicos entre 100-500 $\mu$ s, são entregues a uma taxa de pulso de 10-100 Hz para o grupo muscular, como o músculo quadríceps e os músculos da panturrilha ${ }^{107}$.

A estimulação elétrica $<20 \mathrm{~Hz}$ irá induzir primariamente adaptações como o aumento da capacidade da enzima oxidativa e fibra tipo I proporção ${ }^{32}$, enquanto estimulação elétrica $>50 \mathrm{~Hz}$ irá principalmente induzir adaptações comparáveis ao treinamento de resistência, como um aumento glicolítico capacidade, proporção de fibra tipo II e tamanho da fibra muscular. A EEBF é preferível provavelmente devido à menor fadiga das fibras musculares oxidativas de tipo I, mesmo em pacientes limitados com $\mathrm{IC}^{107}$. Em pacientes com IC, as taxas de pulso entre 10-50 Hz são amplamente utilizadas com melhorias na capacidade funcional e músculo esquelético ${ }^{26,27,97}$.

A intensidade do estímulo é variável, desde um estímulo confortável até o nível de tolerância máxima. No entanto, recomenda-se fortemente que os impulsos sejam administrados com a maior amplitude de pulso ${ }^{108}$. Sabe-se que a magnitude das adaptações musculares e físicas induzidas pelo treinamento físico em pacientes com IC é superior, à medida que ocorre o aumento da intensidade do exercício ${ }^{109}$. A duração da EEBF também parece correlacionarse com a magnitude das adaptações induzidas, com resultados superiores obtidos pelo aumento das horas de aplicação ${ }^{110}$. 


\section{METODOLOGIA}

\subsection{Tipo de estudo}

Trata-se de um Ensaio Clínico Randomizado e mono-cego, com amostragem por coveniência. O processo de randomização dos grupos foi realizado pelo site http://www.random.org. Foi gerado um sorteio eletrônico com base em 30 sujeitos de forma aleatória para as duas condições experimentais: GEEBF e Sham.

\subsection{Sujeitos}

Inicialmente, foram selecionados 254 participantes por prontuários do ambulatório de Cardiologia do Instituto de Cardiologia do Instituto Federal (IC-DF). Posteriormente foram efetuados contatos telefônicos para convidar e verificar se os pacientes atendiam aos critérios de inclusão e exclusão pré-estabelecidos.

Foram adotados como critérios de inclusão: ter idade entre 21-80 anos; apresentar sintomas compatíveis com Classe Funcional (CF) II a IV, de acordo com a American Heart Association (AHA) ${ }^{53}$; apresentar quadro estável em terapia farmacológica por pelo menos um mês antes da coleta de dados; ter fração de ejeção ventricular esquerda $<40 \%$ após confirmação por exame ecográfico.

Foram excluídos indivíduos com: incapacidade de caminhar em uma esteira; possuir doença valvar; angina instável; infarto agudo do miocárdio nos últimos três meses; cardiomiopatia hipertrófica obstrutiva; uso de cardiodesfibrilador interno automático (CDI) ou marcapasso cardíaco; uso crônico de oxigenoterapia; indivíduos que tenham participado de outro ensaio clínico nos últimos 30 dias; ter realizado exercício regular nos últimos seis meses; demonstrar incapacidade de operar uma unidade de EEBF.

Após verificação dos critérios de inclusão e exclusão, 35 sujeitos atenderam aos critérios de elegibilidade, cinco pacientes desistiram de participar do estudo logo no início do tratamento. 30 pacientes foram randomicamente alocados em dois grupos: grupo de eletroestimulação de baixa frequência (GEEBF) e grupo sham (GS). Todos os participantes eram impossibilitados de obter conhecimento sobre qual grupo pertenciam.

No decorrer do estudo, dois participantes faleceram após as avaliações, dois apresentaram problemas de saúde ao iniciar o protocolo, e um do GS não realizou a avaliação final, processo de composição da amostra final representado pela figura 1 . 
Durante a análise dos dados, algumas MMPs não expressaram sua atividade durante a análise por zimografia de gelatina e as demais amostras que se perderam foi devido a problemas técnicos.

Figura 1 - Fluxograma de voluntários

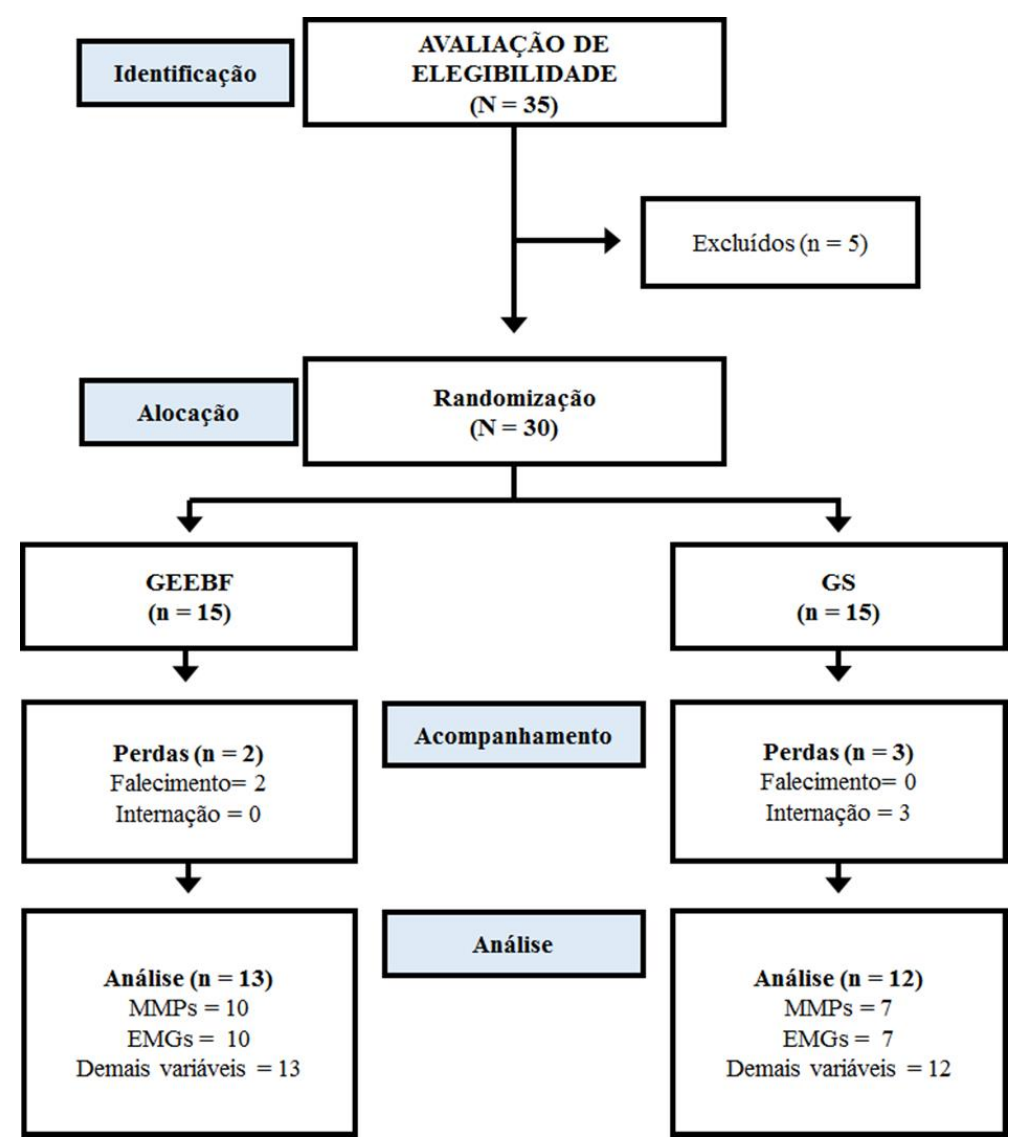

Fonte: Adaptado segundo CONSORT.

Legenda: $\mathrm{N}$ = sujeitos; GS= grupo sham; GEEBF=Grupo de eletroestimulação de baixa frequência; MMPs= metaloproteinases; $\mathrm{TDF}=$ taxa de desenvolvimento de força; $\mathrm{RMS}=$ raiz da média dos quadrados.

\subsection{Desenho Experimental}

As avaliações ecográficas foram realizadas em parceria com clínica particular no Hospital Santa Helena (HSH), em Brasília e as avaliações do teste cardiopulmonar (TECP), avaliações de sangue e o preenchimento de ficha de caracterização foram realizados no Instituto de Cardiologia do Distrito Federal (IC-DF). Já as avaliações de desempenho muscular e o treinamento inicial do aparelho para eletroestimulação para ambos os grupos foram realizados na Faculdade de Educação física (FEF) na Universidade de Brasília (Unb) e no IC-DF, no 
período entre julho de 2015 a maio de 2016. Após autorizar participação, mediante termo de consentimento livre e esclarecido (TCLE -Apêndice A), os indivíduos preencheram uma ficha com dados para a caracterização da amostra (Apêndice B).

A duração total, incluindo as avaliações e a intervenção, foi de quatorze semanas. Antes de iniciar a intervenção, os participantes realizaram uma visita ao HSH (visita 1), para realizar o exame ecocardiográfico, a fim de verificar a função cardíaca. Três dias após, os participantes realizaram teste cardiopulmonar e coleta de sangue no IC-DF (visita 2). Obtiveram o intervalo de uma semana para recuperação das possíveis alterações fisiológicas, decorrentes da aplicação dos testes realizados na visita 2. Na terceira semana foram aplicados testes para verificação do desempenho muscular e foi realizada sessão de familiarização com a primeira orientação para o protocolo de EEBF e GS.

Dois dias após a terceira visita, os participantes iniciaram o treinamento com a eletroestimulação, efetuado de forma domiciliar, com duração de dez semanas. Após seu término, todos os procedimentos realizados nas visitas 1,2 e 3 foram repetidos. Desenho experimental representado na Figura 2.

Figura 2 - Ilustração do experimento

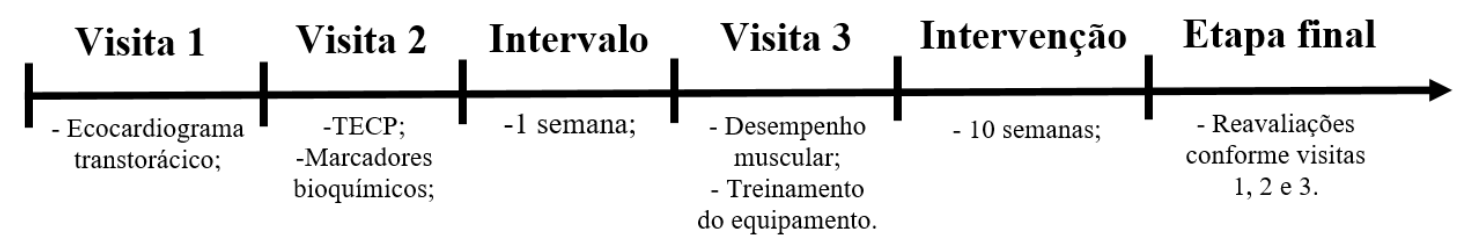

Fonte: Autoria própria.

O estudo foi aprovado pelo Comitê de Ética em Pesquisa da Universidade de Brasília (UnB 115/10), anexo A, e registrado no Clinical Trial.gov (NCT01695421).

\subsection{Procedimentos de avaliação}

5.4.1 Avaliação da função cardíaca

A avaliação foi realizada na posição de decúbito lateral esquerdo, com um sistema de imagem comercialmente disponível, usando um transdutor linear de $4-2 \mathrm{MHz}$ equipado com imagem em segunda harmônica (modelo HDI 5000 MHZ, Philips Advanced Technology Laboratories, Bothell, WA). Para otimizar a visualização da borda endocárdica, foi utilizado 
um sistema de aquisição e arquivamento digital da imagem, em formato DICOM (Digital Imaging and Communication in Medicine) ${ }^{111}$.

Foram obtidas as seguintes variáveis: diâmetro da aorta e diâmetro do átrio esquerdo medidos em milímetros $(\mathrm{mm})$, volume diastólico final em mililitros $(\mathrm{mL})$ e fração de ejeção (FE\%).

5.4.2 Avaliação por biomarcadores de remodelamento muscular, inflamatórios e estresse oxidativo.

As coletas de sangue foram realizadas por técnico habilitado, em concordância com todas as prerrogativas da Agência Nacional de Vigilância Sanitária, utilizando material descartável (agulhas, seringas e luva cirúrgica estéril), algodão com álcool etílico à $70 \%$ e dispensador padronizado para o material perfuro-cortante. Foi realizada punção venosa na veia braquial, utilizando o sistema vacutainer, e após jejum de 12 horas.

As amostras sanguíneas foram coaguladas em temperatura ambiente por dez minutos para separação do plasma e em seguida centrifugadas (Centrífuga, MPW-350R, MPW Med. Instruments, Warsaw, Polônia) a 3000 rpm por dez minutos.

Os biomarcadores foram coletados em tubos heparinizados de $10 \mathrm{~mL}$ e, após a centrifugação, o soro obtido foi distribuído em eppendorfs, que variavam entre 0,5 a $1,5 \mathrm{~mL}$, e armazenado. Essas amostras foram armazenadas em freezer a $-80^{\circ} \mathrm{C}$ para posterior análise.

Biomarcadores de remodelamento muscular

Zimografia de gelatina: Os níveis plasmáticos de isoformas MMP-9 e MMP-2 foram ainda analisados mediante o método de zimografia de gelatina adaptado de Marqueti et al (2008) $)^{112}$. As amostras de plasma foram testadas para identificar a atividade proteolítica das MMPs. A amostra contendo $0,5 \mathrm{uL}$ de plasma será adicionada a $0,5 \mathrm{uL}$ de dodecil sulfato de sódio (SDS) 8\%. Em seguida, as amostras foram passadas no vórtex e após, foi adicionado 10 $\mu \mathrm{L}$ de tampão de amostra sem $\beta$-mercaptoetanol (agente redutor) contendo DSS (20\%) e foram resolvidas por eletroforese em gel de poliacrilamida, contendo DSS e gelatina na concentração final de $1 \mathrm{mg} / \mathrm{ml}$. Após a corrida, o gel foi lavado 2 vezes durante 40 minutos em solução 2,5\% de Triton X-100 para remoção do DSS. O gel foi incubado no tampão de substrato (Tris-HCI $50 \mathrm{mM}$ pH 8,0, $\mathrm{CaCl}_{2} .5 \mathrm{mM} ; \mathrm{NaN}_{3} 0,02 \%$ e $\mathrm{ZnCl}_{2} 10 \mathrm{mM}$ ), a $37^{\circ} \mathrm{C}$, por 20 horas. Após este tempo, foi corado com Coomassie Blue Brilliant R-250 (Bio-Rad) e descorado com ácido acético: metanol: água (1:4:5) para visualização das áreas de atividade. $\mathrm{O}$ equipamento 
ImageMaster 2D Platinum v7.0 (GeneBio) foi utilizado para scanear o gel, visualizar a atividade proteolítica e realizar a análise densitométrica das bandas.

\section{Biomarcadores inflamatórios}

As concentrações de citocinas foram avaliadas por um método de citômetro de fluxo multiplexado utilizando o conjunto de imunoensaios baseados nas normas estabelecidas no Kit de Citocinas Th1/Th2/Th17 humano fabricado pela BD Biosciences® (CBA, San Diego, CA, EUA) de acordo com os protocolos do fabricante. Foram obtidas medições para os seguintes seis mediadores circulantes diferentes: citocinas pró-inflamatórias: Interleucina-2 (IL-2), Interleucina-6 (IL-6), Interferon- $\gamma$ (INF $\gamma$ ) e Fator de necrose tumoral (TNF- $\alpha$ ); E citocinas anti-inflamatórias: Interleucina-4 (IL-4) e Interleucina-10 (IL-10). As citocinas foram medidas em picogramas por mililitro $(\mathrm{pg} / \mathrm{mL})^{113}$.

\section{Biomarcadores de estresse oxidativo}

Mediu-se a capacidade antioxidante, como o poder antioxidante reduzido férrico $(\text { FRAP })^{70}$, o estresse oxidativo pelas substâncias reativas ao ácido tiobarbitúrico (TBARS) e a vasodilatação periférica pela indução da sintase do óxido nítrico (iSON) ${ }^{114}$, utilizando uma espectroscopia UV-visível com um leitor de microplacas (SpectraMax® M3 MultiMonocromática) controlada por um software de análise (SoftMax®) medido em micromoles/litro $(\mu \mathrm{mol} / \mathrm{L})$.

\subsubsection{Avaliação da capacidade cardiopulmonar}

Foi aplicado o protocolo de rampa em esteira (T2100, GE Health Care, EUA, Waukesha), com ergoespirometria aberta (MedGraphics VO2000® - Medical Graphics Corp., St. Paul, MN), que é apropriado para pacientes com diminuição da capacidade aeróbica ${ }^{115}$. Anteriormente à realização de cada teste, foram calibrados os sensores de oxigênio $\left(\mathrm{O}_{2}\right)$ e gás carbônico $\left(\mathrm{CO}_{2}\right)$ com concentrações padrão de $\mathrm{O}_{2}, \mathrm{CO}_{2}$ e nitrogênio. A velocidade inicial foi de $27 \mathrm{~m} \cdot \mathrm{min}^{-1}$ e estabilizada após 2 minutos em $64 \mathrm{~m} \cdot \mathrm{min}^{-1} 0 \%$. A inclinação inicial foi de $0 \%$ e incrementada em $0,5 \%$ a cada 15 segundos, sobre contínua monitorização com eletrocardiograma de 12 canais, até que o participante pedisse para interromper o teste. A 
pressão arterial foi avaliada a cada dois minutos, utilizando um dispositivo manual (Durashock DS44, Tycos Welch Allyn, Saint Joseph, EUA), imagem da realização do TECP pode ser observada na figura 3.

Os gases expirados foram coletados usando um sensor na peça bocal, sendo analisados a cada oito respirações. $\mathrm{O}$ valor médio dos últimos dez segundos foi utilizado para definir o consumo de oxigênio pico $\left(\mathrm{V}_{2} \mathrm{em} \mathrm{mL} \cdot \mathrm{kg}^{-1} \cdot \mathrm{min}^{-1}\right)$. $\mathrm{O}$ método dos equivalentes ventilatórios foi usado para determinar o limiar ventilatório. Os dados das médias dos dez segundos de $\mathrm{VE}$ e $\mathrm{VCO}_{2}$, desde o início do exercício até o pico, foram tabulados em software de planilha eletrônica (Microsoft Excel, Microsoft Corp, de Bellevue, WA) para calcular o slope $\mathrm{VE} / \mathrm{VCO}_{2}$ via regressão linear dos mínimos quadrados $(\mathrm{y}=\mathrm{mx}+\mathrm{b}, \mathrm{m}=\mathrm{slope}){ }^{116}$.

Após a interrupção do teste, todos os indivíduos obtiveram intervalo de recuperação (IR) ativo de dois minutos com carga de trabalho de baixa intensidade, seguido por IR passivo de cinco minutos na posição sentada. A frequência cardíaca, eletrocardiograma, pressão arterial e gases expirados continuaram sendo monitorados durante os cinco minutos de IR ${ }^{117}$.

As variáveis avaliadas por meio do teste cardiopulmonar foram diretas e indiretas obtidas por meio do comportamento do $\mathrm{VO}_{2}, \mathrm{VCO}_{2}$, VE e FC.

Figura 3 - Realização do Teste de esforço cardiopulmonar com coleta de variáveis ventilatórias pelo uso de peça bocal

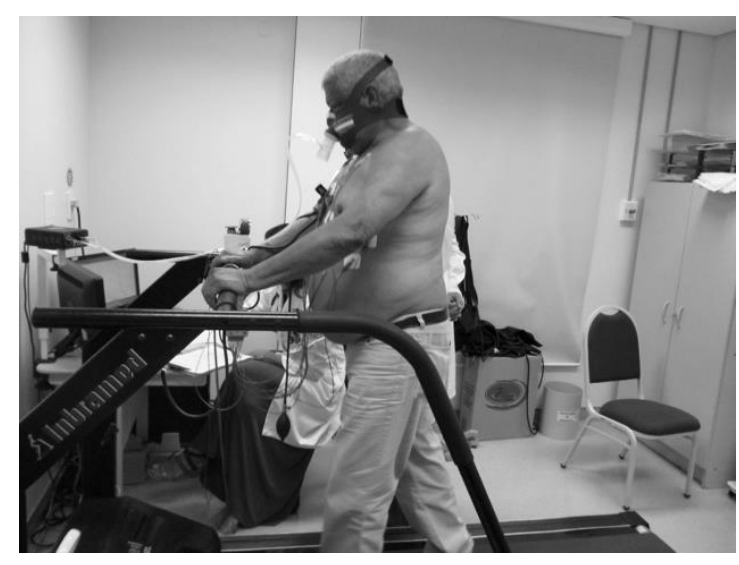

Fonte: Autoria própria

5.4.4. Avaliação do desempenho muscular

Para avaliação do desempenho muscular, foram avaliadas a força muscular, por meio da dinamometria isocinética, e a ativação muscular, por meio da eletromiografia de superfície. 


\subsubsection{Dinamômetro isocinético}

A avaliação do pico de torque (PT) foi realizada no sistema Dinamômetro Isocinético Biodex III (Biodex Medical Inc., EUA), figura 4. O programa Biodex Advantage versão 3 foi utilizado para o registro e estocagem dos dados. Os sinais foram adquiridos por meio da uma interface DB-15 fêmea 63, que provê os sinais analógicos em tempo real do torque, velocidade angular e posição angular ${ }^{118}$. Um adaptador foi construído, a fim de obter os sinais da interface a partir de três diferentes conectores até uma placa digitalizadora (BNC-2120, National Instruments, TX, EUA), que faz uma amostragem dos sinais em $2.000 \mathrm{~Hz}$.

Figura 4 - Avaliação da força isométrica dos extensores de joelho no Dinamômetro Isocinético

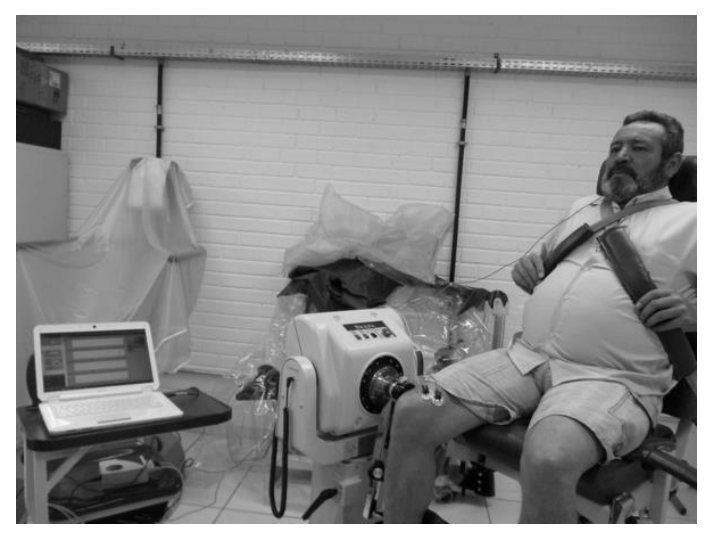

Fonte: Autoria própria

Todos os procedimentos foram realizados com a perna dominante dos voluntários. Os sujeitos foram posicionados na cadeira do dinamômetro isocinético com o quadril posicionado a 100 de flexão e o joelho a $90^{\circ}$ de flexão $\left(0^{\circ} \text { de extensão total }\right)^{119}$. O braço de alavanca afixado $\approx 3$ centímetros acima do maléolo lateral da fíbula e o eixo de rotação do dinamômetro alinhado ao epicôndilo lateral do fêmur. Os sujeitos foram estabilizados na cadeira do dinamômetro isocinético por meio de cintas diagonais, pélvica e de tornozelo. A calibração do dinamômetro foi realizada de acordo com as especificações do manual do fabricante ${ }^{118}$. Os participantes receberam o feedback visual em tempo real, fornecido pelo equipamento e foram encorajados verbalmente a realizar o esforço máximo.

O protocolo foi composto por três contrações voluntárias isométricas máximas (CVIM), cada CVIM teve duração de 5 segundos com IR de 2 minutos entre as repetições. Foi considerado o maior pico de torque entre as três repetições ${ }^{119}$. 


\subsubsection{Eletromiografia de Superfície (EMGs)}

Foi registrada a eletromiografia de superfície (EMGs) do músculo vasto medial com um eletromiógrafo de superfície portátil de quatro canais (Miotool, Miotec Equipamentos Biomédicos Ltda, Brasil), com resolução de 14bits, nível de ruído < 2LSB e modo de rejeição comum de $110 \mathrm{~dB}$, a fim de monitorar a ativação muscular.

A colocação dos eletrodos foi baseada nas recomendações do Surface Electromyography for the Non-Inavasive Assessment of Muscles (SENIAM) ${ }^{120}$, figura 5. Os eletrodos utilizados foram ativos simples diferencial (impedância de entrada de 10 Ohm) possuem espuma de polietileno com adesivo medicinal hipoalérgico, gel sólido aderente e contato bipolar de $\mathrm{Ag} / \mathrm{AgCl}$ (Medi-Trace ${ }^{\mathrm{TM}}$ 100, Covidien, EUA), com distância de 20mm entre os pólos de captação.

Figura 5 - Ilustrações do posicionamento dos eletrodos de EMG em músculo vasto medial (A) e vértebra C7 (B).

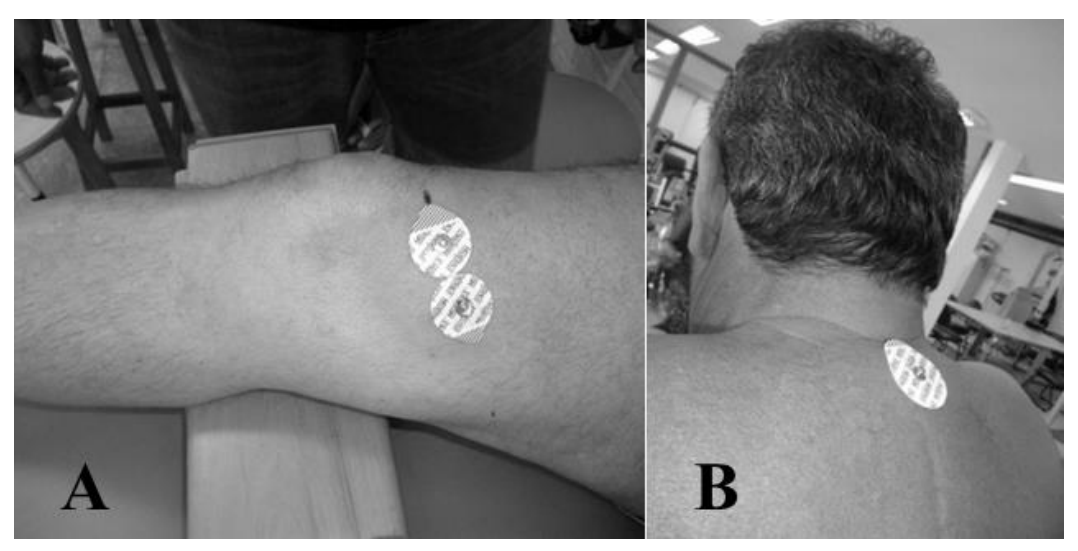

Fonte: Autoria própria.

O eletrodo de referência foi acoplado na proeminência óssea da sétima vértebra cervical (C7). Eles foram conectados (por meio de um cabo extensor) a um pré-amplificador de alta impedância, e os sinais foram ajustados a uma amostragem de $2.000 \mathrm{~Hz}$ e um ganho final de 1000 vezes nos canais habilitados. Antes da colocação dos eletrodos, a área foi tricotomizada e, em seguida, realizada uma leve abrasão com álcool 70\%. O posicionamento dos eletrodos paralelos às fibras musculares foi adotado para garantir que as barras de captação estivessem perpendiculares às fibras e, desta forma, o sinal captasse o maior número possível de unidades motoras. 
5.4.4.3. Processamento dos sinais eletromiográficos

Foi utilizado o software MatLab versão 6.5 (MathWorks Inc., Natick, MA, EUA) para processar os sinais eletromiográficos adquiridos mediante uma rotina específica desenvolvida. O filtro utilizado para o processamento dos sinais foi um Butterworth, passabaixa de segunda ordem, com frequência de corte em $10 \mathrm{~Hz}$.

O sinal eletromiográfico da contração isométrica voluntária máxima (CIVM), de cada sujeito, foi utilizado para normalizar o sinal dinâmico com janelas de 0,025 segundos (50 amostras) onde o sinal eletromiográfico isométrico foi retificado e a média calculada.

Os valores da velocidade angular e torque foram processados, identificados pelo início e fim do load range em cada repetição. Estes pontos são definidos como os valores acima de $95 \%$ da velocidade angular utilizada $(60 \%)$.

Durante a contração voluntária máxima (CIVM), foram calculadas três taxas de desenvolvimento de força estáticas (TDFe). As TDFes foram calculadas como a derivada média do sinal de torque entre o valor limiar de 8 N.m, representado pelo asterisco verde e os tempo de 30, 50, 100 e 150 milissegundos, representados pelo asterisco vermelho, relativos ao valor limiar, conforme Figura $6^{119}$.

Figura 6 - Sinal de eletromiografia de torque isométrico do reto femoral e vasto medial

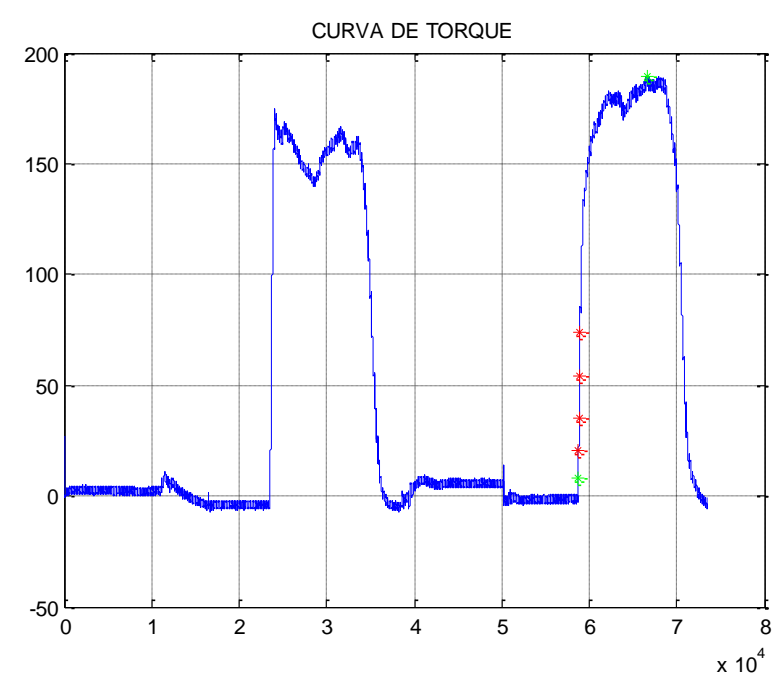

Fonte: Autoria própria. 
5.4.5 Tratamento de eletroestimulação

Os pacientes foram submetidos ao protocolo de eletroestimulação de baixa frequência (GEEBF) ou grupo sham (GS) uma vez por dia, 5 dias por semana, durante 10 semanas.

Para o GEEP um equipamento de eletroestimulação portátil (BLD Stim³ San Diego, USA) foi configurado para enviar uma onda quadrada bifásica simétrica, com frequência de $25 \mathrm{hz}$, duração de pulso de $400 \mu \mathrm{s}$, tempo estimulação e repouso de 10 segundos ${ }^{34}$. Para o GS foi entregue o mesmo equipamento, contudo o voluntário foi orientado apenas ligar e desligar o equipamento e instruído que ao ligar o equipamento após o posicionamento dos eletrodos ele já estaria recebendo uma estimulação em sua musculatura.

Os pacientes foram orientados a fazer o treinamento sentados, de modo a garantir que o joelho ficasse posicionado aproximadamente a 90 graus. Foram afixados quatro eletrodos adesivos (50x90mm, Eco-Patch ${ }^{\mathrm{TM}}$, Promed Specialties Hunting Valley,PA) bilateralmente em membros inferiores sob os músculos quadríceps e gastrocnêmicos. Os pontos de fixação dos eletrodos foram: ponto motor proximal do músculo reto femoral $(\cong 25 \mathrm{~cm}$ acima da borda

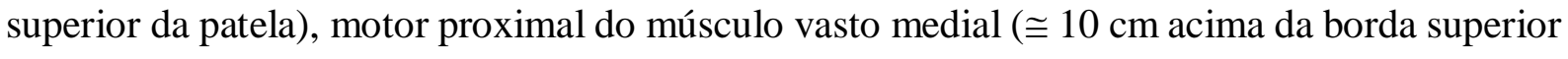
medial da patela), ponto motor do gastrocnêmico medial $(\cong 10 \mathrm{~cm}$ acima e medialmente da porção póstero-superior da tuberosidade do calcâneo) e o ponto motor do gastrocnêmico lateral

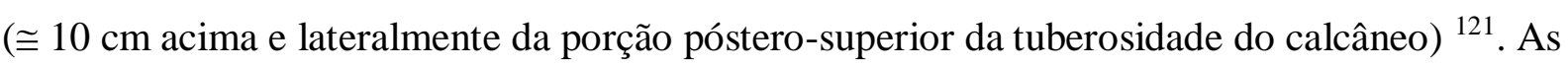
marcações dos pontos motores foram realizadas pelo fisioterapeuta com caneta dermatográfica de longa duração, figura 7.

Antes de ser iniciado o treinamento via estimulação elétrica, a magnitude da corrente a ser aplicada era determinada. A intensidade da corrente era gradativamente aumentada a cada $5 \mathrm{~mA}$, até que o paciente relatasse ter alcançado o máximo nível de tolerância com contração muscular visível.

O tratamento foi aplicado durante uma hora, tanto para o grupo experimental quanto para o GS tendo sido mantida constante a intensidade da corrente aplicada. Este procedimento foi efetuado mediante supervisão de um fisioterapeuta. Durante os três dias que precederam as reavaliações, a intensidade da corrente aplicada foi mantida constante. 
Figura 7 - Ilustrações da colocação dos eletrodos da eletroestimulação nas musculaturas vasto medial (A), reto femoral (A), e cabeça proximal do gastrocnêmico (B).

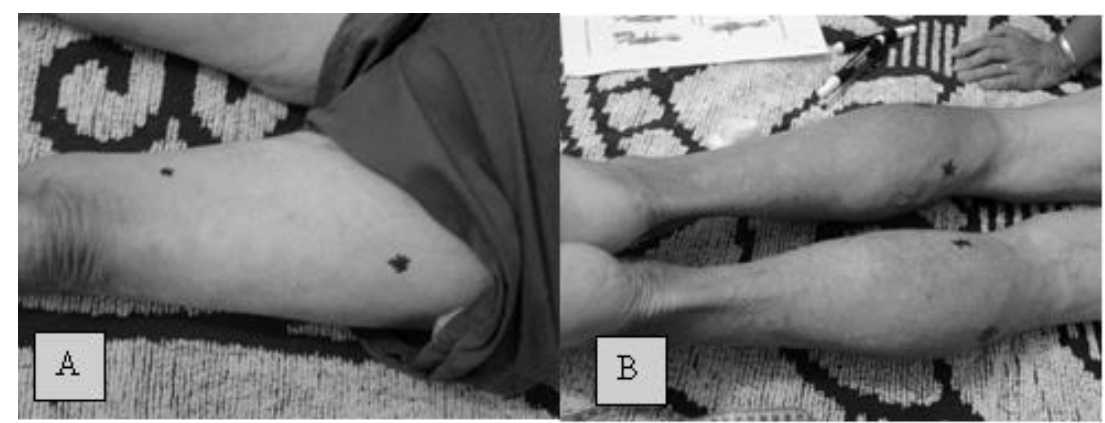

Fonte: Autoria própria

\section{ANÁLISE ESTATÍSTICA}

Dados expressos como média, desvio padrão $( \pm \mathrm{DP})$ e porcentagem $(\%)$. A normalidade da distribuição foi verificada utilizando-se o teste de Shapiro Wilk. Para a comparação entre os resultados das variáveis dependentes (remodelamento muscular, marcadores inflamatórios, estresse oxidativo, desempenho muscular e capacidade cardiopulmonar), recorreu-se à ANOVA two-way. Toda a análise estatística foi realizada por meio do programa Sigma Plot 12.0 (Systat Software Inc, San José, CA). Em todas as situações foi considerado o nível de confiança de $5 \%(p \leq 0,05)$.

Considerando o comportamento da variável MMP2 Ativa, que demonstrou uma diferença de 8,1 unidade arbitrária (UA) no grupo experimental, e 0,31 UA no grupo sham, verificou-se um poder de $99 \%$ para um erro alfa de $5 \%$. Os cálculos foram realizados por meio do software $\mathrm{G}^{*}$ Power 3.1.9.2, Kiel, Alemanha). 


\section{RESULTADOS}

Foram avaliados 26 participantes, os quais foram randomizados em dois grupos, grupo de estimulação elétrica de baixa frequência (GEEBF) e grupo sham (GS). Os grupos foram semelhantes, com predomínio do sexo masculino, idade média de 50 anos, predomínio de sobrepeso e predominância etiológica isquêmica e chagásica. Houve um predomínio de diabetes mellitus no grupo intervenção. A distribuição da classe funcional (CF) pela NYHA variou entre os grupos sem diferença significativa. Houve um discreto predomínio do uso de betabloqueador no grupo intervenção, sem diferença com relação às demais classes de medicamentos. Características basais estão apresentadas na Tabela 1.

Tabela 1 - Características clínicas, antropométricas e funcionais dos pacientes com IC submetidos a eletroestimulação.

\begin{tabular}{|c|c|c|}
\hline $\begin{array}{c}\text { Variáveis } \\
\text { Antropométricos }\end{array}$ & GEEBF $(n=13)$ & GS $(n=12)$ \\
\hline Idade (anos) & $51,2 \pm 8,5$ & $53,7 \pm 9,8$ \\
\hline Estatura (cm) & $166,7 \pm 9,1$ & $165,7 \pm 10,4$ \\
\hline Peso (Kg) & $74,5 \pm 18,8$ & $76,7 \pm 17$ \\
\hline $\operatorname{IMC}\left(\mathrm{Kg} / \mathrm{m}^{2}\right)$ & $26,5 \pm 4,6$ & $27,7 \pm 3,7$ \\
\hline \multicolumn{3}{|l|}{ Sexo, $n(\%)$} \\
\hline Masculino & $10(76,9)$ & $9(69,2)$ \\
\hline Feminino & $3(23,1)$ & $4(30,8)$ \\
\hline \multicolumn{3}{|l|}{ Fatores de Risco, $\mathbf{n}(\%)$} \\
\hline Obesidade & $2(15,4)$ & $2(15,4)$ \\
\hline Ex- Fumantes & $13(100)$ & $12(100)$ \\
\hline Diabetes mellitus & $12(92,3)$ & $9(69,2)$ \\
\hline \multicolumn{3}{|l|}{ Etiologia, $\mathbf{n}(\%)$} \\
\hline Isquêmica & $7(53,8)$ & $7(53,8)$ \\
\hline Chagas & $6(46,2)$ & $6(46,2)$ \\
\hline \multicolumn{3}{|l|}{ Classe Funcional (\%) } \\
\hline NYNHA (II/III/IV) & $\begin{array}{c}7 / 4 / 4 \\
(53,8 / 30,8 / 15,4)\end{array}$ & $\begin{array}{c}3 / 3 / 7 \\
(23,1 / 23,1 / 46,2)\end{array}$ \\
\hline \multicolumn{3}{|l|}{ Ecocardiograma } \\
\hline Diâmetro AE (mm) & $46,3 \pm 4,4$ & $48,7 \pm 7,4$ \\
\hline Fração de Ejeção (\%) & $30 \pm 5,5$ & $29,1 \pm 7,4$ \\
\hline \multicolumn{3}{|l|}{ Medicamentos, $\mathbf{n},(\%)$} \\
\hline Diurético & $10(76,9)$ & $10(76,9)$ \\
\hline Espironolactona & $11(84,6)$ & $10(76,9)$ \\
\hline IECA/ARA II & $12(92,3)$ & $11(84,6)$ \\
\hline Digoxina & $4(30,8)$ & $7(53,8)$ \\
\hline Beta-bloqueador & $13(100)$ & $11(84,6)$ \\
\hline
\end{tabular}

Legenda: Dados contínuos representados em média e DP e dados categóricos em frequência total e relativa (\%), GS: grupo sham; GEEBF: grupo estimulação de baixa frequência; IC: Insuficiência Cardíaca; IMC: Índice de massa corporal; IECA/ARAII: Inibidores da Enzima Conversora da Angiotensina/antagonistas dos receptores angiotensina II; NYNHA: New York Heart Association. Dados apresentados em média e desvio padrão ( \pm ), frequência e porcentagem (\%). 
Biomarcadores de remodelamento muscular

O remodelamento muscular mensurado pelos níveis de MMP-2 ativa entre os grupos intervenção e sham variou $\Delta 8,10$ vs $\Delta 0,31$, respectivamente, $\operatorname{com} p=0,0241$ no grupo intervenção, enquanto no grupo sham não houve alterações estatisticamente significativas ( $p$ = 0,99) (Gráfico 1).

Gráfico 1 - Comparativo dos níveis de concentração plasmático da metaloproteinase -2 ativa em pacientes com insuficiência cardíaca frente ao tratamento de eletroestimulação de baixa frequência.

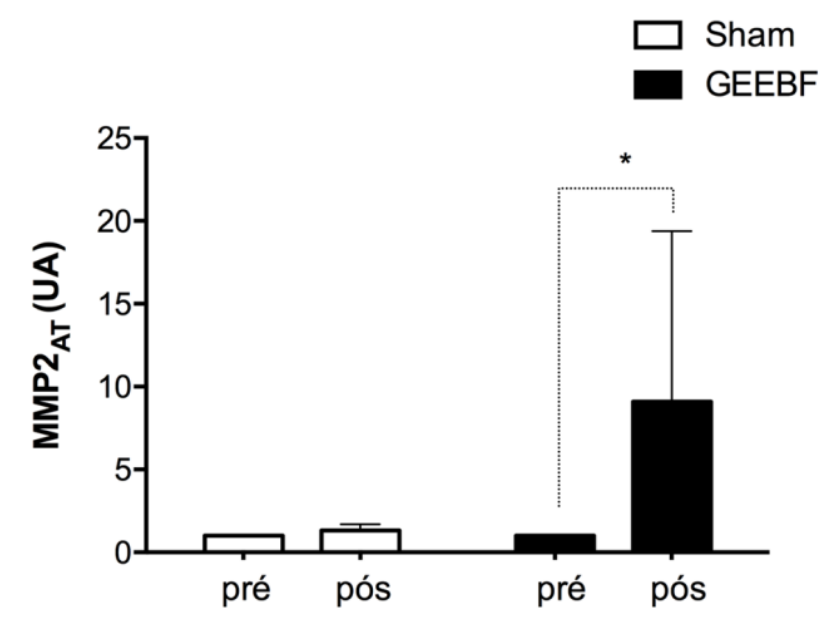

Legenda: Níveis de MMP-2 expressos em unidades arbitrárias (UA). MMP-2: Matriz extracelular - 2;. GEEBF = Eletroestimulação de Baixa Frequência.; GS = grupo sham; (*) indica um valor de $\mathrm{p} \leq 0,05$ );

Quanto à resposta inflamatória no músculo cardíaco, foi observada mudanças significativas no comparativo entre os grupos intervenção e sham nos níveis de concentração da MMP-9 com variação $\Delta-0,34$ vs $\Delta+0,11$, respectivamente, com $p=0,042$ no grupo intervenção, enquanto no grupo sham não houve alterações estatisticamente significativas ( $p=$ 0,104), Gráfico 2. 
Gráfico 2 - Comparativo dos níveis de concentração plasmático da metaloproteinase - 9 ativa em pacientes com insuficiência cardíaca frente a tratamento de estimulação elétrica de baixa frequência.

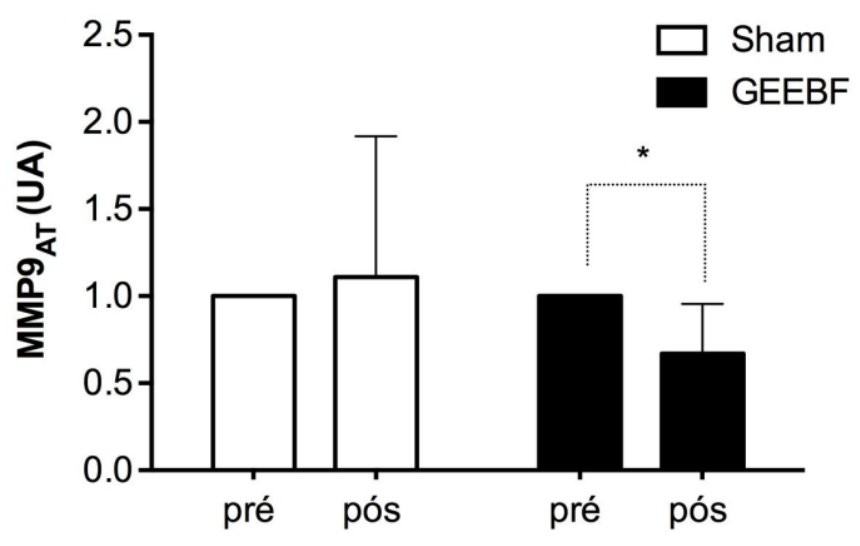

Legenda: Níveis de MMP-9 expressos em unidades arbitrárias (UA). MMP-9: Matriz extracelular - 9;. GEEBF = Eletroestimulação de Baixa Frequência.; GS = grupo sham; $(*)$ indica um valor de p $\leq 0,05)$;

Biomarcadores inflamatórios

Nas respostas pró-inflamatórias, observa-se uma maior redução do fator de necrose tumoral $\alpha($ TNF- $\alpha)$ no grupo GEEBF ( $\mathrm{p}=0,049)$ em relação ao GP $(-41 \%$ vs $-2 \%)$, sem diferenças significativas entre os grupos $(\mathrm{p}=0,375)$, conforme gráfico 3 .

Gráfico 3 - Comparativo dos níveis de concentração plasmático do fator de necrose tumoral em pacientes com insuficiência cardíaca frente ao tratamento de eletroestimulação de baixa frequência.

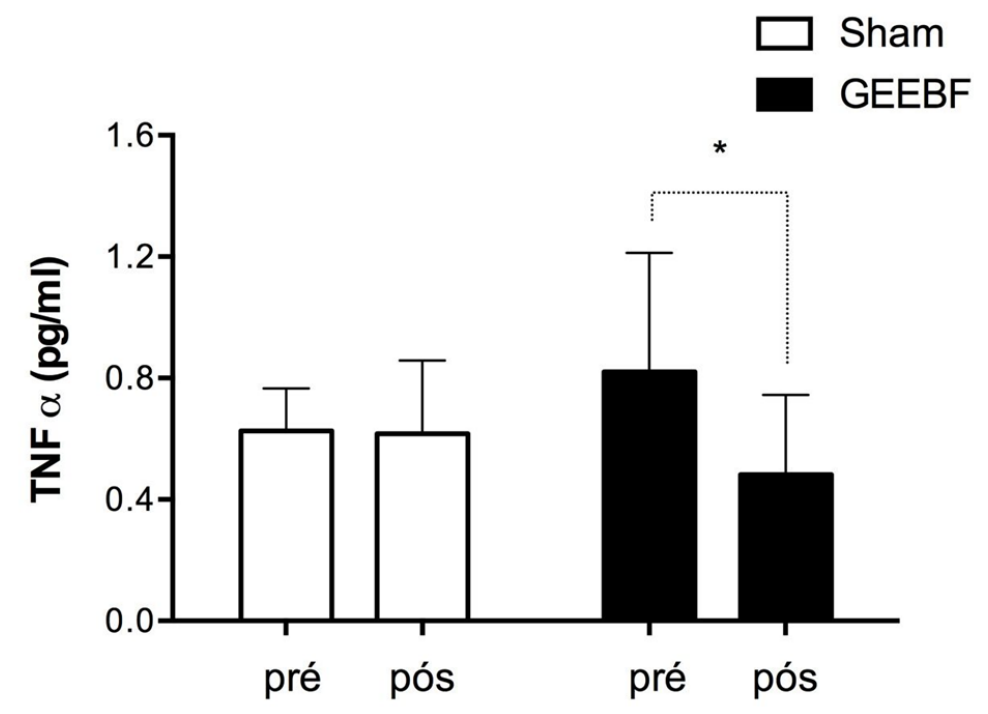

Legenda: TNF- $\alpha=$ Fator de necrose tumoral medido; $\mathrm{pg} / \mathrm{mL}=$ picogramas por mililitro; GS = grupo sham; GEEBF = Eletroestimulação de Baixa Frequência.; (*) indica um valor de $\mathrm{p} \leq 0,05)$;

Não foram observadas mudanças significativas no comparativo entre os grupos intervenção e sham para as variáveis pró-inflamatórias $(\Delta \mathrm{INF}-\gamma,-0,76$ vs $-0,2 ; \Delta \mathrm{IL}-2,+0,04$ vs 
$+0,39 ; \Delta \mathrm{IL}-6,+0,01$ vs $-1,49)$ e anti-inflamatórias ( $\Delta \mathrm{IL}-4,-0,16$ vs $+0,35 ; \Delta \mathrm{IL}-10,-0,33$ vs $+0,02$ ), respectivamente, com $\mathrm{p}>0,05$ (tabela 2).

Tabela 2 - Comparativo dos níveis de concentração de citocinas no plasma em pacientes com insuficiência cardíaca frente a ao tratamento de eletroestimulação de baixa frequência.

\begin{tabular}{lccccc|cc}
\hline $\begin{array}{c}\text { Variáveis } \\
(\mathbf{p g} / \mathbf{m L})\end{array}$ & Marcadores & \multicolumn{2}{c}{ GEEBF } & \multicolumn{2}{c|}{ GS } & \multirow{2}{*}{ Cohen's $\boldsymbol{d}$} & $\begin{array}{c}\text { Tamanho } \\
\text { do Efeito }\end{array}$ \\
\hline & & Pré & Pós & Pré & Pós & & 0.24 \\
Pró- & INF- $\gamma$ & $4,91 \pm 2,23$ & $4,15 \pm 0,42$ & $4,16 \pm 0,42$ & $3,96 \pm 0,31$ & 0.49 & 0.07 \\
inflamatórias & IL-2 & $4,13 \pm 0,65$ & $4,17 \pm 0,45$ & $3,98 \pm 0,37$ & $4,37 \pm 1,04$ & 0.14 & -0.01 \\
& IL-6 & $6,05 \pm 5,16$ & $6,06 \pm 5,23$ & $6,95 \pm 6,54$ & $5,46 \pm 4,52$ & -0.02 & -0.09 \\
Anti- & IL-4 & $0,65 \pm 0,61$ & $0,49 \pm 0,33$ & $0,47 \pm 0,23$ & $0,82 \pm 0,52$ & -0.18 & 0.24 \\
inflamatórias & IL-10 & $2,84 \pm 1,76$ & $2,51 \pm 2,38$ & $1,89 \pm 0,64$ & $1,91 \pm 0,90$ & 0.50 & 0.96 \\
\hline
\end{tabular}

Legenda: INF- $\gamma=$ interferon alfa; IL-2= interleucina-2; IL-6=interleucina 6; IL-4=interleucina 4; IL-10= interleucina 10; pg/ml= picogramas/mililitros. Dados apresentados em média e desvio padrão ( \pm ). Comparação dos grupos pela ANOVA twoway. GS=grupo sham; GEEBF=Eletroestimulação de Baixa Frequência.

\section{Biomarcadores de estresse oxidativo}

Na tabela 3 abaixo, foram apresentados os valores de três variáveis relacionadas ao estresse oxidativo. Não houve diferenças significativas no comparativo entre os grupos intervenção e sham nos níveis FRAP $(\Delta+0,8$ vs -9$)(\mathrm{P}=0,831)$, TBARS $(\Delta-0,08$ vs $-0,02)$ $(\mathrm{P}=0,5298)$ e iSNO $(\Delta+0,22$ vs $+0,49)(\mathrm{p}=0,103)$, respectivamente.

Tabela 3 - Comparativo dos níveis de concentração no plasma de estresse oxidativo em pacientes com insuficiência cardíaca frente ao tratamento de eletroestimulação de baixa frequência.

\begin{tabular}{lcccccc}
\hline $\begin{array}{l}\text { Variáveis } \\
(\boldsymbol{\mu} \mathbf{m o l} / \mathbf{L})\end{array}$ & Pré & Pós & Pré & Pós & Cohen's $\boldsymbol{d}$ & $\begin{array}{c}\text { Tamanho } \\
\text { do efeito }\end{array}$ \\
\hline FRAP & $130,7 \pm 40,9$ & $131,5 \pm 37,6$ & $138,2 \pm 51,77$ & $129,20 \pm 52,76$ & -0.057 & -0.03 \\
TBARS & $2,9 \pm 0,75$ & $2,88 \pm 0,48$ & $4,0 \pm 1,19$ & $3,92 \pm 1,62$ & -0.99 & -0.44 \\
iSNO & $20,49 \pm 1,61$ & $20,98 \pm 1,77$ & $19,7 \pm 1,27$ & $19,92 \pm 2,60$ & 0.51 & 0.25 \\
\hline
\end{tabular}

Legenda: FRAP = capacidade total de redução do Ferro; TBARS= substâncias reativas ao ácido tiobarbitúrico; iSNO = indução da sintetase do óxido nítrico; $\mu \mathrm{mol} / \mathrm{L}=$ micromoles / litro. Dados apresentados em média e desvio padrão ( \pm ). Comparação dos grupos pela ANOVA twoway. GS=grupo sham; GEEBF=Eletroestimulação de Baixa Frequência. 
Avaliação da capacidade cardiopulmonar

Não houve mudanças nas variáveis de capacidade cardiorrespiratória entre os grupos intervenção e sham avaliada pelo $\mathrm{V}_{2}(\Delta+0,27$ vs $+1,1)(\mathrm{p}=0,3479)$ e pelo $\mathrm{V}$-slope $(\Delta+2,8$ vs $-0,15)(\mathrm{p}=0,5972)$, conforme a tabela 4 .

Tabela 4 - Comparativo das variáveis de capacidade cardiorrespiratória em pacientes com insuficiência cardíaca frente ao tratamento de eletroestimulação de baixa frequência.

\begin{tabular}{|c|c|c|c|c|c|c|c|}
\hline \multirow{2}{*}{\multicolumn{2}{|c|}{ Variáveis }} & \multicolumn{2}{|c|}{ GEEBF } & \multicolumn{2}{|c|}{ GS } & \multirow{2}{*}{ Cohen's d } & \multirow{2}{*}{$\begin{array}{c}\text { Tamanho } \\
\text { do efeito }\end{array}$} \\
\hline & & Pré & Pós & Pré & Pós & & \\
\hline \multirow{2}{*}{ CPET } & $\dot{\mathrm{V}} \mathrm{O}_{2}(\mathrm{~mL} / \mathrm{kg} \cdot \mathrm{min})$ & $18,74 \pm 3,7$ & $19,01 \pm 4,06$ & $16,05 \pm 4,57$ & $17,15 \pm 4,87$ & 0.53 & 0.25 \\
\hline & V-slope & $33 \pm 5,47$ & $35,8 \pm 10,7$ & $36,15 \pm 7,87$ & $36 \pm 7,05$ & -0.22 & -0.12 \\
\hline
\end{tabular}

Legenda: $\grave{V}_{2}=$ consumo de oxigênio; $\mathrm{V}$-slope = relação do volume minuto com o dióxido de carbono. Dados apresentados em média e desvio padrão $( \pm)$. Comparação dos grupos pela ANOVA twoway. GS=grupo sham; GEEBF=Eletroestimulação de Baixa Frequência.

Desempenho muscular

Não foram observadas alterações significativas no desempenho muscular entre os grupos intervenção e sham avaliado pelo pico de torque $(\Delta+1,6$ vs -0.6$)(\mathrm{p}=0,531)$, TDF $(\Delta+6,61$ vs $+6,32)(\mathrm{p}=0,307)$ e no RMS $(\mathrm{p}=0,731)$, conforme tabela 5 .

Tabela 5 - Comparativo das variáveis de desempenho muscular em pacientes com insuficiência cardíaca frente ao tratamento com eletroestimulação de baixa frequência.

\begin{tabular}{|c|c|c|c|c|c|c|}
\hline \multirow{2}{*}{ Variáveis } & \multicolumn{2}{|c|}{ GEEBF } & \multicolumn{2}{|c|}{ GP } & \multirow{2}{*}{ Cohen's d } & \multirow{2}{*}{$\begin{array}{l}\text { Tamanho } \\
\text { do efeito }\end{array}$} \\
\hline & Pré & Pós & Pré & Pós & & \\
\hline PT (N.M) & $176 \pm 56,8$ & $177,6 \pm 54,6$ & $160,2 \pm 37,4$ & $159,6 \pm 39,1$ & 0.35 & 0.17 \\
\hline TDF (N.m.s $\left.{ }^{-1}\right)$ & $22,61 \pm 4,18$ & $29,22 \pm 14,3$ & $15,78 \pm 7,13$ & $22,1 \pm 7,3$ & 0.84 & 0.39 \\
\hline RMS & $0,03 \pm 0,02$ & $0,03 \pm 0,02$ & $0,03 \pm 0,03$ & $0,03 \pm 0,01$ & 0 & 0 \\
\hline
\end{tabular}

Legenda: $\mathrm{PT}=$ pico de torque; $\mathrm{TDF}=$ taxa de desenvolvimento de força; RMS = root mean square. Dados apresentados em média e desvio padrão ( \pm ). Comparação dos grupos pela ANOVA twoway. GS=grupo sham; $\mathrm{GEEBF}=$ Eletroestimulação de Baixa Frequência. 


\section{DISCUSSÃO}

Este é o primeiro estudo realizado com EEBF com o objetivo de avaliar o efeito de um programa domiciliar de reabilitação com EEBF sobre os biomarcadores de remodelamento muscular, inflamação, estresse oxidativo, capacidade cardiorrespiratória e desempenho muscular de pacientes com IC. A hipótese da investigação foi que a EEBF poderia estimular o remodelamento muscular, diminuir a atividade inflamatória e aumentar a capacidade de antioxidantes, promover ganho da capacidade cardiorrespiratória e desempenho muscular. Entretanto, a EEBF foi capaz apenas de estimular as enzimas relacionadas a atividade de remodelamento muscular e reduzir a atividade inflamatória. Enquanto que a hipótese que a EEBF aumentaria a capacidade oxidativa, ativação das fibras musculares, capacidade cardiorrespiratória e da força muscular foram refutadas.

\section{Metalloproteinases}

Nossos achados indicam que a EEBF induz o aumento nas concentrações da MMP2. Esse resultado pode ser explicado, pois as MMP'S são ativadas mediante estímulos mecânicos que, a depender da intensidade, da duração e do tipo de estímulo ${ }^{123}$, podem provocar adaptações no músculo esquelético ${ }^{124}$. Essas adaptações consistem em aumento da produção de colágeno, reestruturação das fibras musculares e aumento da síntese proteica e todos esses aspectos promovem o remodelamento muscular ${ }^{125}$. Entretanto, esse é o primeiro estudo que avalia o efeito da EEBF na MMP's em humanos.

Os estudos que avaliam o níveis das MMP-2 em outras formas de intervenção utilizadas na reabilitação de pacientes com IC com capacidade funcional apta à realização de exercício aeróbico ${ }^{18}$ e exercício resistivo ${ }^{37,39,126}$ observaram a mesma elevação dessa variável. Os achados apresentados reforçam o fato de a EEBF ser um recurso que promove remodelamento muscular, sugerindo uma interação do músculo com o tecido conjuntivo, adaptações essas que clinicamente podem favorecer o ganho de força no paciente com IC.

Também foi observado que a EEBF reduz os níveis de concentração da MMP-9 no plasma. Isso acontece, pois o processo de remodelamento muscular ocorre de forma progressiva em resposta a estímulos exógenos crônicos promovendo a adaptação muscular sem ocasionar formação de fibrose, com estruturação das fibras musculares, consequentemente, reduzindo as respostas inflamatórias que ocorrem durante esse processo ${ }^{40,41,126}$. 
Este também é o primeiro estudo que avalia o efeito da EEBF nos níveis de concentração de MMP-9 em humanos. Os estudos em animais com EEBF não demonstram alteração da MMP-9, apesar do aumento da remodelação ${ }^{42,43,127}$, enquanto em treinamento aeróbico e de resistência utilizados em programas de reabilitação, reduzem substancialmente esse marcador, como resposta crônica ao exercício ${ }^{39-41,126}$.

Clinicamente, esses resultados são promissores, pois indicam que o uso de eletroestimulação de baixa frequência promove uma adaptação muscular com redução do estado inflamatório. Desta forma, criam uma pré-condição favorável ao paciente que será submetido a um programa regular de reabilitação baseado em exercício.

\section{Respostas inflamatórias}

Ao analisarmos o efeito da EEBF verificamos uma redução da TNF- $\alpha$ dentre as citocinas pró-inflamatórias, sem influencia, no entanto, nas interleucinas anti-inflamatória. $\mathrm{O}$ único estudo encontrado que avaliou o efeito do EEBF no TNF- $\alpha$, IL-6 e IL-10 foi o de Karavidas et al. Karavidas demonstrou que a eletroestimulação foi capaz de reduzir de forma significativa o TNF- $\alpha$ sem alteração das demais citocinas corroborando com os nossos resultados. Contudo, o autor justifica esses achados indicando que a EEBF é capaz de reduzir a produção de radicais livres, possivelmente em decorrência de uma ativação endotelial ${ }^{34}$, que não foi avaliada em nosso estudo. Como descrito anteriormente, no entanto, a modulação do TNF- $\alpha$, avaliada em nosso estudo, pode ter sido pela alteração da matriz extracelular, refutando desta forma o racional proposto por Karavidas et al.

Acreditamos que os estímulos elétricos foram capazes de induzir a modulação da matriz extracelular (MMP-2 e MMP-9). Essa matriz pode ter promovido um mecanismo indireto de regulação de fluxo de células para o foco inflamatório refletindo no decréscimo do TNF- $\alpha^{59,123,128}$. Nossos achados indicam que a redução do TNF- $\alpha$ indica uma diminuição no processo inflamatório crônico, sem alterações nas respostas imunes. Esse efeito, no entanto, pode não ter ocorrido em magnitude suficiente capaz de sobrepujar o estado inflamatório basal, habitualmente encontrado em pacientes com insuficiência cardíaca ${ }^{128}$.

\section{Respostas Oxidativas}

Não observamos nesse estudo a influência da EEBF sobre as variáveis de estresse oxidativo. Esses achados podem ser explicados, pois apesar de o uso de eletroestimulação inverter a ordem de recrutamento de unidades motoras ${ }^{129}$, a corrente de baixa frequência 
favorece o recrutamento de fibras do tipo I resistentes à fadiga ${ }^{32}$, enquanto a estimulação de alta frequência aumenta o recrutamento das fibras do tipo II-A responsáveis pela contração rápida. O maior recrutamento de fibras de contração rápida em detrimento das fibras de contração lenta parece aumentar o estresse oxidativo ${ }^{129-133}$.

Além do mecanismo de recrutamento de fibras, existem outros que podem influenciar o metabolismo muscular, como mudanças nos níveis de antioxidantes. Esse foi o primeiro estudo em estresse oxidativo que utilizou a variável TBARS para verificar se o EEBF poderia, por meio da via de peroxidação lipídica, reduzir os níveis de estresse oxidativo, contudo essa hipótese foi refutada. Esse resultado pode ser explicado, pois a redução do TBARS tem sido inversamente relacionada à fração de ejeção $(\mathrm{FE} \%)^{134,135}$ e diretamente relacionada à redução de citocinas anti-inflamatórias, neste estudo não foram observadas mudança nesses aspectos.

Outro biomarcador avaliado neste estudo foi a indução da sintetase do óxido nítrico iSNO, considerado um importante marcador de vasodilatação periférica. Alguns estudos já demonstram o efeito favorável da EEBF na vasodilatação periférica local por meio da dilatação do fluxo-mediada (FMD) na artéria braquial ${ }^{34,99,105,106}$. Apesar dos resultados promissores, os estudos não são conclusivos em afirmar se esses benefícios ocorrem de forma local ou sistêmica ${ }^{97}$. Karavidas sugere em seu estudo, que esse seria um possível mecanismo para explicar a melhora da atividade vascular, o que não foi verificado em nosso estudo. A eletroestimulação pode estimular um aumento na circulação periférica pelo mecanismo de bombeamento (contração muscular), melhorando o redirecionamento de fluxo ao musculo esquelético ${ }^{136}$ que não está relacionado ao mecanismo de hipóxia ou inflamatório presentes na resposta do $\mathrm{iSNO}^{137},{ }^{22}$.

\section{Capacidade Cardiorrespiratória}

Em nosso estudo, a EEBF não foi capaz produzir melhora da capacidade funcional, por meio de aumento do $\grave{\mathrm{V}}_{2}$ e redução do V-slope. Recente meta-análise os autores compararam o uso da eletroestimulação com exercício aeróbico, demonstrando que o treinamento baseado em exercício foi mais eficaz do que a EEBBF para melhorar o $\mathrm{V}_{2} \mathrm{em}$ pacientes com IC, mas concluíram que a eletroestimulação é um método a ser considerado para potencializar os efeitos do treinamento ${ }^{97}$. Nesse, ao comparar o grupo que utilizou a eletroestimulação ao grupo que não realizava exercício ${ }^{32,34,138}$, verificou-se um aumento do $\dot{V}$ $\mathrm{O}_{2}$ nos pacientes que usaram a eletroestimulação. Contudo, dos três estudos, apenas Nuhr e 
colaboradores explicaram como randomizaram a amostra, por meio de envelopes, mas não houve cegamento dos avaliadores ${ }^{32}$.

Em relação ao V-slope, Dobsak 2012 avaliou dezenove pacientes com IC com FE $<40 \%$ submetidos a protocolo de EEBF domiciliar 2 vezes por dia, com duração de 60 minutos, 7 dias da semana, por 12 semanas, e comparou essa intervenção a um grupo que realizou treinamento aeróbico por 10 semanas com cicloergômetro, em que a carga foi progressivamente ajustada até a tolerância do participante. $\mathrm{O}$ autor verificou que nem o grupo com EEBF nem o de treinamento aeróbico foram capazes de reduzir os parâmetros de slope ${ }^{35}$ corroborando com o nosso achado.

\section{Desempenho Muscular}

Pico de torque isométrico articular do joelho

Em nosso estudo não foi observado alteração na medida pico de torque pela EEBF. Foram encontrados seis artigos que avaliaram o efeito da eletroestimulação na população com pacientes com IC com fração de ejeção $<35 \%^{31,103,104,138-140}$ e avaliaram a força muscular. Dentre eles, apenas dois estudos são ensaios clínicos randomizados ${ }^{103,138}$ e apenas um estudo utilizou a $\mathrm{EEBF}^{138}$.

Banerjee et al realizaram a EEBF com baixa frequência $(4 \mathrm{~Hz})$ e alta intensidade (300mA), sem descrever, no entanto, a característica pulso. O estudo crossover utilizou os mesmos participantes por 8 semanas sem uso de corrente e, com duas semanas de intervalo, aplicou a eletroestimulação por mais 8 semanas, 1 hora por dia, 5 vezes por semana. As avaliações de capacidade funcional e força foram realizadas em momento basal, 8 semanas e 18 semanas $^{138}$.

Em nosso estudo realizamos dez semanas de EBBF com uma frequência de 25hz, com largura de pulso de 400ms, intensidade máxima tolerável, suficiente para gerar contração visível (média utilizada foi de aproximadamente $70 \mathrm{~mA}$ ). Os pacientes foram divididos aleatorizados em grupos diferentes (EBBF ou sham), tendo as variáveis avaliadas no momento basal e após dez semanas.

Diversos fatores podem ter influenciado a divergência nos resultados, dentre eles, A mudança do quadro clínico pode ter influenciado nas respostas, haja vista que ambos os grupos foram acompanhados ao mesmo tempo no estudo de Banerje e as avaliações foram 
realizadas antes e após os protocolos. Em nosso estudo, pode ter ocorrido a sobreposição de efeito dos protocolos, já que estes se iniciavam com a realização de atividades diárias ativas.

Taxa de desenvolvimento de Força

A taxa de aumento do torque depende da ativação muscular e tem sido demonstrado que as taxas máximas de força desenvolvimento só podem ser obtidas com altas frequências de Estimulação elétrica ${ }^{142,143}$. Apesar do aumento de $17 \%$ da ativação muscular nesse estudo com o uso de baixa frequência, a ativação não foi suficiente para gerar alterações na força.

Ativação muscular do vasto medial

A ativação muscular nesse estudo com o uso de baixa frequência foi verificada pela variável RMS da eletromiografia de superfície (EMG). Observou-se que a EEBF não modificou a ativação muscular. Nossos achados podem ser justificados, pois deve-se considerar na aplicação da eletroestimulação aspectos que afetam a ativação muscular são a frequência, a intensidade da corrente e aspectos fisiológicos ${ }^{144}$.

Nuhr 2004 avaliou o recrutamento de fibras musculares por biópsia no músculo vasto lateral, após programa de baixa frequência realizado todos os dias, duas vezes ao dia, por 10 semanas $^{32}$. Ele observou um aumento da expressão proteica da cadeia pesada de miosina tipo I, o que representa uma geração de energia para contração muscular. Nuhr estabeleceu 100mA sem alteração de intensidade até o fim do protocolo; em nossa metodologia, a intensidade foi ajustada progressivamente com a tolerância do paciente.

Contudo, Babault et al avaliaram por ultrassonografia que a eletroestimulação de baixa frequência com intensidade ajustável de acordo com a tolerância do paciente é capaz de alterar a arquitetura muscular do quadríceps como resposta aguda, mas sugerem mais estudos para compreensão dessas alterações ${ }^{145}$.

Nossos achados mostram que a EEBF com intensidade ajustável a percepção de tolerância do paciente parece não ter sido suficiente para promover mudança significativa na ativação muscular.

Como limitações do estudo, não foi possível o cegamento do fisioterapeuta responsável pela aplicação da EEBF, uma vez que a intensidade da estimulação devia ser regulada a cada semana conforme a tolerância do paciente à corrente aplicada. No entanto, os 
examinadores e os pacientes não sabiam sobre as intervenções aplicadas. Não foi possível realizar controle sobre as atividades de vida diária.

Este estudo orientou o treinamento com EEBF em um ângulo de flexão do joelho $\left(90^{\circ}\right)$ e avaliou também nessa angulação. Pode ter havido uma possível alteração no torque após o período de treinamento neste ângulo, o que é caracterizado como uma limitação do estudo. Sugerem-se estudos futuros em que a avaliação com o dinamômetro isocinético seja realizado em mais de um ângulo articular ${ }^{143}$. 


\section{CONCLUSÃO E CONSIDERAÇÕES FINAIS}

A EEBF foi capaz de estimular biomarcadores de remodelamento muscular (metaloproteinase do tipo 2) e reduzir biomarcadores de inflamação (MMP-9 e TNF-alfa). Estas alterações, no entanto, não estiveram relacionadas ao aumento da capacidade oxidativa e não houve alterações nas variáveis de desempenho muscular e capacidade cardiopulmonar.

Apesar dos resultados positivos com o uso da EEBF, considerando a complexidade do processo e a diversidade das MMPs, devem ser realizados novos ensaios clínicos controlados e randomizados, avaliando o efeito da EEBF como intervenção prévia ou complementar sobre os biomarcadores, com o objetivo de buscar melhor entendimento desses efeitos em pacientes com insuficiência cardíaca. 


\section{REFERÊNCIAS}

1. Andrade JP De, Siciliano A, David J, Neto DS, Moreira LF, Teixeira RA, et al. III Diretriz Brasileira de Insuficiência Cardíaca Crônica. 2009;93:1-71.

2. SBC. Atualização da diretriz brasileira de insuficiência cardíaca crônica - 2012. Soc Bras Cardiol. 2012;98:1-33.

3. Nogueira PR, Rassi S, Corrêa K de S. Perfil epidemiológico, clínico e terapêutico da insuficiência cardíaca em hospital terciário. Vol. 95, Arquivos Brasileiros de Cardiologia. 2010. p. 392-8.

4. Heitzer T, Baldus S, Von Kodolitsch Y, Rudolph V, Meinertz T. Systemic endothelial dysfunction as an early predictor of adverse outcome in heart failure. Arterioscler Thromb Vasc Biol. 2005;25:1174-9.

5. Witman MAH, McDaniel J, Fjeldstad AS, Ives SJ, Zhao J, Nativi JN, et al. A Differing Role of Oxidative Stress in the Regulation of Central and Peripheral Hemodynamics during Exercise in Heart Failure. AJP: Heart and Circulatory Physiology. 2012.

6. Maron MS, Udelson JE. Left Ventricular Remodeling in Heart Failure Current Concepts in Clinical Significance and Assessment. JCMG [Internet]. 2011;4(1):98108. Available from: http://dx.doi.org/10.1016/j.jcmg.2010.10.008

7. Brunjes DL, Dunlop M, Wu C, Jones M, Kato TS, Kennel PJ, et al. Analysis of Skeletal Muscle Torque Capacity and Circulating Ceramides in Patients with Advanced Heart Failure. 2016;22(5):347-55.

8. Tor C, Cardiol P. Fisiopatologia da Insuficiência Cardíaca Crónica [39]. 2009;(December 2008):439-71.

9. Harrington D, Anker SD, Chua TP, Webb-Peploe KM, Ponikowski PP, Poole-Wilson P a, et al. Skeletal muscle function and its relation to exercise tolerance in chronic heart failure. J Am Coll Cardiol [Internet]. 1997 Dec;30(7):1758-64. Available from: http://www.ncbi.nlm.nih.gov/pubmed/9385904

10. Piepoli MF, Crisafulli A. Pathophysiology of human heart failure: importance of skeletal muscle myopathy and reflexes. Exp Physiol [Internet]. 2014;99:609-15. Available from: http://www.scopus.com/inward/record.url?eid=2-s2.084897077731\&partnerID=tZOtx3y1

11. Mangner N, Weikert B, Scott Bowen T, Sandri M, Höllriegel R, Erbs S, et al. Skeletal muscle alterations in chronic heart failure: Differential effects on quadriceps and diaphragm. J Cachexia Sarcopenia Muscle. 2015;6(4):381-90.

12. Shen Y, Zhang X, Ma W, Song H, Gong ZHU, Wang Q, et al. VE / VCO 2 slope and its prognostic value in patients with chronic heart failure. 2015;1407-12.

13. Giuliano C, Karahalios A, Neil C, Allen J, Levinger I. The effects of resistance training on muscle strength , quality of life and aerobic capacity in patients with chronic heart failure - A meta-analysis. Int J Cardiol [Internet]. 2016; Available from: http://dx.doi.org/10.1016/j.ijcard.2016.11.023

14. Journal AI, Theodorou AA, Panayiotou G, Volaklis KA, Douda HT, Paschalis V, et al. Aerobic, resistance and combined training and detraining on body composition, muscle strength, lipid profile and inflammation in coronary artery disease patients. 2016;8627(June). 
15. Gayda M, Merzouk A, Choquet D, Ahmaidi S. Assessment of Skeletal Muscle Fatigue in Men With Coronary Artery Disease Using Surface Electromyography During Isometric Isometric Contraction of Quadriceps Muscles Mathieu. 2005;86(February):210-5.

16. Gayda M. Effects of exercise training modality on skeletal muscle fatigue in men with coronary heart disease. J Electromyogr Kinesiol [Internet]. 2009;19(2):e32-9. Available from: http://dx.doi.org/10.1016/j.jelekin.2007.08.009

17. Brassard P, Maltais F, Noël M, Doyon J. Skeletal muscle endurance and muscle metabolism in patients with chronic heart failure. 2006;22(5):387-92.

18. Gatta L, Armani A, Iellamo F, Consoli C, Molinari F, Caminiti G, et al. Effects of a short-term exercise training on serum factors involved in ventricular remodelling in chronic heart failure patients. Int J Cardiol [Internet]. 2012;155(3):409-13. Available from: http://dx.doi.org/10.1016/j.ijcard.2010.10.045

19. Adamopoulos S, Parissis J, Karatzas D, Kroupis C, Georgiadis M, Karavolias G, et al. Physical training modulates proinflammatory cytokines and the soluble Fas/soluble Fas ligand system in patients with chronic heart failure. J Am Coll Cardiol. 2002;39(4):653-63.

20. Linke A, Adams V, Schulze PC, Erbs S, Gielen S, Fiehn E, et al. Antioxidative effects of exercise training in patients with chronic heart failure: Increase in radical scavenger enzyme activity in skeletal muscle. Circulation. 2005;111:1763-70.

21. Niebauer J. Effects of exercise training on inflammatory markers in patients with heart failure. Vol. 13, Heart Failure Reviews. 2008. p. 39-49.

22. Gielen S, Adams V, Mo S, Linke A, Erbs S, Yu J, et al. Anti-Inflammatory Effects of Exercise Training in the Skeletal Muscle of Patients With Chronic Heart Failure. 2003;42(5).

23. Meirelles LR De, Matsuura C, Resende ADC, Salgado ÂA, Rodrigues N, Coscarelli PG, et al. Chronic exercise leads to antiaggregant, antioxidant and anti-inflammatory effects in heart failure patients. 2013;

24. Maddocks M, Nolan CM, Man WD, Polkey MI, Hart N, Gao W, et al. Neuromuscular electrical stimulation to improve exercise capacity in patients with severe COPD : a randomised double-blind, placebo-controlled trial. Lancet Respir [Internet]. 2016;4(1):27-36. Available from: http://dx.doi.org/10.1016/S2213-2600(15)00503-2

25. Jones S, Wdc M, Gao W, Ij H, Wilcock A, Maddocks M. Neuromuscular electrical stimulation for muscle weakness in adults with advanced disease ( Review ). 2016;(10).

26. Smart NA, Dieberg G, Giallauria F. Functional electrical stimulation for chronic heart failure: A meta-analysis. Int J Cardiol [Internet]. 2013;167(1):80-6. Available from: http://dx.doi.org/10.1016/j.ijcard.2011.12.019

27. Sbruzzi G, Ribeiro R a, Schaan BD, Signori LU, Silva AM V, Irigoyen MC, et al. Functional electrical stimulation in the treatment of patients with chronic heart failure: a meta-analysis of randomized controlled trials. Eur J Cardiovasc Prev Rehabil [Internet]. 2010;17(3):254-60. Available from: http://www.ncbi.nlm.nih.gov/pubmed/20560163

28. Neves LMT, Cahalin LP, Silva VZM, Silva ML, Arena R, Spielholz NI, et al. Effect of chronic neuromuscular electrical stimulation on primary cardiopulmonary exercise test variables in heart failure patients: A systematic review and meta-analysis. IJC Metab Endocr [Internet]. 2014;5:28-35. Available from: http://www.journals.elsevier.com/ijc- 
metabolic-andendocrine/\%5Cnhttp://ovidsp.ovid.com/ovidweb.cgi?T=JS\&CSC=Y \&NEWS=N\&PA $\mathrm{GE}=$ fulltext $\& \mathrm{D}=\mathrm{emed} 12 \& \mathrm{AN}=2014620008 \% 5 \mathrm{Cnhttp} / / \mathrm{sfx}$. scholarsportal.info/uhn?sid =OVID:embase $\&$ id=pmid: $\&$ id=doi:10.1016/j.ijcme.2014.09.003\&issn=2

29. Gomes Neto M, Oliveira FA, Reis HFC dos, de Sousa Rodrigues- E, Bittencourt HS, Carvalho VO. Effects of Neuromuscular Electrical Stimulation on Physiologic and Functional Measurements in Patients With Heart Failure: A SYSTEMATIC REVIEW WITH META-ANALYSIS. J Cardiopulm Rehabil Prev [Internet]. 2016;1. Available from: http://content.wkhealth.com/linkback/openurl?sid=WKPTLP:landingpage\&an=012731 16-900000000-99700\%5Cnhttp://www.ncbi.nlm.nih.gov/pubmed/26784735

30. Groehs R V., Antunes-Correa LM, Nobre TS, Alves M-JN, Rondon MUP, Barreto ACP, et al. Muscle electrical stimulation improves neurovascular control and exercise tolerance in hospitalised advanced heart failure patients. Eur J Prev Cardiol [Internet]. 2016; Available from: http://cpr.sagepub.com/lookup/doi/10.1177/2047487316654025

31. Quittan M, Sochor A, Wiesinger GF, Kollmitzer J, Sturm B, Pacher R, et al. Strength Improvement of Knee Extensor Muscles in Patients with Chronic Heart Failure by Neuromuscular Electrical Stimulation. Artif Organs [Internet]. 1999 May 1;23(5):4325. Available from: http://dx.doi.org/10.1046/j.1525-1594.1999.06372.x

32. J. Nuhr M. Beneficial effects of chronic low-frequency stimulation of thigh muscles in patients with advanced chronic heart failure. Eur Heart J [Internet]. 2004 Jan [cited 2014 Sep 11];25(2):136-43. Available from: http://eurheartj.oxfordjournals.org/cgi/doi/10.1016/j.ehj.2003.09.027

33. Saitoh M, Rodrigues M, Anker M, Anker D, Haehling S Von, Springer J. Neuromuscular electrical stimulation for muscle wasting in heart failure patients. Int $\mathbf{J}$ Cardiol [Internet]. 2016; Available from: http://dx.doi.org/10.1016/j.ijcard.2016.09.127

34. Karavidas AI, Raisakis KG, Parissis JT, Tsekoura DK, Adamopoulos S, Korres D a, et al. Functional electrical stimulation improves endothelial function and reduces peripheral immune responses in patients with chronic heart failure. Eur J Cardiovasc Prev Rehabil. 2006;13(4):592-7.

35. Dobšák P, Tomandl J, Spinarova L, Vitovec J, Dusek L, Novakova M, et al. Effects of Neuromuscular Electrical Stimulation and Aerobic Exercise Training on Arterial Stiffness and Autonomic Functions in Patients With Chronic Heart Failure. Artif Organs. 2012;36(10):920-30.

36. Lu P, Takai K, Weaver VM, Werb Z. Extracellular Matrix degradation and remodeling in development and disease. Cold Spring Harb Perspect Biol. 2011;3(12).

37. da Cunha Nascimento D, de Cassia Marqueti Durigan R, Tibana RA, Durigan JL, Navalta JW, Prestes J. The Response of Matrix Metalloproteinase-9 and -2 to Exercise. Sports Med. 2014;269-78.

38. Carmeli E, Moas M, Reznick AZ, Coleman R. Matrix metalloproteinases and skeletal muscle: a brief review. Muscle Nerve. 2004;29:191-7.

39. Urso ML, Pierce JR, Alemany JA, Harman EA, Nindl BC. Effects of exercise training on the matrix metalloprotease response to acute exercise. Eur J Appl Physiol. 2009;106(5):655-63.

40. Kadoglou NPE, Vrabas IS, Sailer N, Kapelouzou A, Fotiadis G, Noussios G, et al. Exercise ameliorates serum MMP-9 and TIMP-2 levels in patients with type 2 diabetes. 
Diabetes Metab. 2010;36(2):144-51.

41. Niessner A, Richter B, Penka M, Steiner S, Strasser B, Ziegler S, et al. Endurance training reduces circulating inflammatory markers in persons at risk of coronary events: Impact on plaque stabilization? Atherosclerosis. 2006;186(1):160-5.

42. Russo TL, Peviani SM, Durigan JLQ, Fátima Salvini T. Electrical stimulation increases matrix metalloproteinase-2 gene expression but does not change its activity in denervated rat muscle. Muscle and Nerve. 2008;37(5):593-600.

43. Koskinen SO, Kjaer M, Mohr T, Sørensen FB, Suuronen T, Takala TE. Type IV collagen and its degradation in paralyzed human muscle: effect of functional electrical stimulation. Muscle Nerve [Internet]. 2000;23(4):580-9. Available from: http://www.ncbi.nlm.nih.gov/pubmed/10716770

44. Cipriano G, Maria L, Neves T, França G, Cipriano B, Chiappa GR, et al. ScienceDirect Cardiovascular Disease Prevention and Implications for Worksite Health Promotion Programs in Brazil. Prog Cardiovasc Dis [Internet]. 2014;56(5):493-500. Available from: http://dx.doi.org/10.1016/j.pcad.2013.10.018

45. Albuquerque DC De, David J, Neto DS, Bacal F, Eduardo L, Rohde P, et al. I Registro Brasileiro de Insuficiência Cardíaca - Aspectos Clínicos , Qualidade Assistencial e Desfechos Hospitalares. 2015;

46. Mozaffarian D, Benjamin EJ, Go AS, Arnett DK, Blaha MJ, Cushman M, et al. AHA Statistical Update Heart Disease and Stroke Statistics — 2015 Update A Report From the American Heart Association WRITING GROUP MEMBERS. 2015.

47. Saúde. M da. Datasus: mortalidade - 1996 a 2012, no Brasil pela CID-10. 2012;http://tabnet.datasus.gov.br/cgi/deftohtm.exe?sim/.

48. Pimenta P, Spineti DM, Souza AS De, Garcia MI, Xavier SS. Acurácia do relacionamento probabilístico de registros na identificação de óbitos em uma coorte de pacientes com insuficiência cardíaca descompensada Accuracy of probabilistic record linkage for identifying deaths in a cohort of patients with decompensate. 2016;32(1):18.

49. Kemp CD, Conte J V. The pathophysiology of heart failure. Cardiovasc Pathol [Internet]. 2012;21(5):365-71. Available from: http://dx.doi.org/10.1016/j.carpath.2011.11.007

50. Y-r C. AHA Scientific Statement Measurement of Reactive Oxygen Species, Reactive Nitrogen Species, and Redox-Dependent Signaling in the Cardiovascular System. Vol. 119, Circ Res. 2016. 1-38 p.

51. Ganesh V. Halade, PhD, Yu-Fang Jin, PhD, and Merry L. Lindsey P. Matrix Metalloproteinase (MMP)-9: a proximal biomarker for cardiac remodeling and a distal biomarker for inflammation. 2014;139(1):32-40.

52. Josiak K, Jankowska EA, Piepoli MF, Banasiak W, Ponikowski P. Skeletal myopathy in patients with chronic heart failure: significance of anabolic-androgenic hormones. $\mathrm{J}$ Cachexia Sarcopenia Muscle. 2014;5(4):287-96.

53. Butler J, Casey DE, Drazner MH, Fonarow GC, Geraci SA, Horwich T, et al. 2013 ACCF / AHA Guideline for the Management of Heart Failure. JAC [Internet]. 2013;62(16):e147-239. Available from: http://dx.doi.org/10.1016/j.jacc.2013.05.019

54. Thomas RJ, King M, Lui K, Oldridge N, Piña IL, Spertus J. AACVPR/ACCF/AHA 2010 Update: Performance measures on cardiac rehabilitation for referral to cardiac 
rehabilitation/secondary prevention services: A report of the American Association of Cardiovascular and Pulmonary Rehabilitation and the American College . J Cardiopulm Rehabil Prev [Internet]. 2010 [cited 2014 Sep 9];30(5):279-88. Available from: http://www.ncbi.nlm.nih.gov/pubmed/20808157

55. Peter L. Matrix metalloproteinases in cardiovascular disease. 2006;22(February):2530 .

56. Cogni AL, Farah E, Minicucci MF, Azevedo PS, Okoshi K, Matsubara BB, et al. Artigo Original Metaloproteinases 2 e 9 são Preditoras de Remodelação Ventricular Esquerda após o Infarto do Miocárdio. Arq Bras Cardiol. 2013;315-21.

57. Bujak M, Frangogiannis NG. The role of IL-1 in the pathogenesis of heart disease. 2009;165-76.

58. Fail CH. Transforming Growth Factor- ${ }_{\llcorner}{ }_{\llcorner}$Governing the Transition From Inflammation to Fibrosis in Heart Failure With Preserved Left Ventricular Function. Circ Hear Fail. 2011;

59. Chakrabarti S, Zee JM, Patel KD. Regulation of matrix metalloproteinase-9 (MMP-9) in TNF-stimulated neutrophils: novel pathways for tertiary granule release. J Leukoc Biol [Internet]. 2006;79(1):214-22. Available from: http://www.ncbi.nlm.nih.gov/pubmed/16275891

60. Cheung P, Sawicki G, Wozniak M. Matrix Metalloproteinase-2 Contributes to Ischemia-Reperfusion Injury in the Heart. 2000;1833-9.

61. Bonnema DD, Webb CS, Pennington WR, Stroud RE, Leonardi AMYE, Clark LL, et al. Effects of Age on Plasma Matrix Metalloproteinases ( MMPs ) and Tissue Inhibitor of Metalloproteinases ( TIMPs ). 2007;13(7):530-40.

62. Kherif S, Dehaupas M, Lafuma C, Fardeau M, Alameddine HS. Matrix metalloproteinases MMP-2 and MMP-9 in denervated muscle and injured nerve. Neuropathol Appl Neurobiol. 1998;24:309-19.

63. Beber ARC, Polina ER, Biolo A, Santos BL. Matrix Metalloproteinase-2 Polymorphisms in Chronic Heart Failure : Relationship with Susceptibility and LongTerm Survival. 2016;1-15.

64. Barra K, Barbosa F, Maria N, Costa B, Paula ODE, Minim PR, et al. Estresse oxidativo : conceito, implicações e fatores modulatórios Oxidative stress : concept , implications. 2010;23(4):629-43.

65. Candia AM de, Villacorta Júnior H, Mesquita ET. Ativação imune-inflamatória na insuficiência cardíaca. Vol. 89, Arquivos Brasileiros de Cardiologia. 2007.

66. Kashyap MK, Yadav V, Sherawat BS, Jain S, Kumari S, Khullar M, et al. Different antioxidants status, total antioxidant power and free radicals in essential hypertension. Mol Cell Biochem. 2005;277(1-2):89-99.

67. Halliwell B. Lipid peroxidation, antioxidants and cardiovascular disease: How should we move forward? Cardiovasc Res. 2000;47(3):410-8.

68. Schneider, $\mathrm{C}$ and Oliveira A. Radicais livres de oxigênio e exercício : mecanismos de formação e adaptação ao treinamento físico *. 2004;10(9):308-13.

69. Belló-klein A, Souza-rabbo MP, Barp J, Llesuy S. SOCIEDADE de CARDIOLOGIA do RIO GRANDE DO SUL. 2004;(18):1-4.

70. Benzie IF, Strain JJ. The ferric reducing ability of plasma (FRAP) as a measure of 
“antioxidant power": the FRAP assay. Anal Biochem. 1996;239:70-6.

71. Silva FL, Mazzotti NG, Picoral M, Nascimento DM, Isabel M, Martins M, et al. Infarto do miocárdio experimental e aumento do estresse oxidativo em diafragma de ratos. 2005;31(6):506-10.

72. Cotton JM, Kearney MT, Shah AM. Nitric oxide and myocardial function in heart failure: friend or foe ? 2002;564-6.

73. Words EY. Óxido nítrico : o simples mensageiro percorrendo a complexidade . Metabolismo, síntese e funções . 2000. :265-71.

74. Niebauer J, Clark AL, Webb-peploe KM, Coats AJS. Exercise training in chronic heart failure : effects on pro-inflammatory markers. 2005;7:189-93.

75. Strassburg S, Springer J, Anker SD. Muscle wasting in cardiac cachexia. Int J Biochem Cell Biol. 2005;37:1938-47.

76. Anker SD, Haehling S Von. INFLAMMATORY MEDIATORS IN CHRONIC HEART FAILURE : AN OVERVIEW. 2004;

77. Chakrabarti S, Zee JM, Patel KD. Regulation of matrix metalloproteinase-9 (MMP-9) in TNF-stimulated neutrophils: novel pathways for tertiary granule release. J Leukoc Biol. 2006;79(1):214-22.

78. Cecília A, Nóbrega DT. Imunossenescência : a relação entre leucócitos, citocinas e doenças crônicas. 2008;

79. Michaud M, Balardy L, Moulis G, Gaudin C, Peyrot C, Vellas B, et al. Proinflammatory Cytokines, Aging, and Age-Related Diseases. 2013;

80. Frangogiannis NG. Regulation of the Inflammatory Response in Cardiac Repair. 2012;

81. Kim JB, Hama S, Hough G, Navab M, Fogelman AM, Maclellan WR, et al. Heart Failure is Associated With Impaired Anti-Inflammatory and Antioxidant Properties of High-Density Lipoproteins. Am J Cardiol [Internet]. 2013;112(11):1770-7. Available from: http://dx.doi.org/10.1016/j.amjcard.2013.07.045

82. Adamopoulos S, Parissis J, Kroupis C, Georgiadis M, Karatzas D, Karavolias G, et al. Physical training reduces peripheral markers of inflammation in patients with chronic heart failure. Eur Heart J [Internet]. 2001 May [cited 2014 Aug 14];22(9):791-7.

Available from: http://www.ncbi.nlm.nih.gov/pubmed/11350112

83. Lopes RD, Lopes AC. Review Article Anti-inflammatory Effect of Physical Training in Heart Failure : Role of. 2008;643-51.

84. England TN. Exercise capacity and mortality among men referred for Exercise Testing. 2002;346(11):793-801.

85. ElGuindy A, Yacoub MH. Heart failure with preserved ejection fraction. Glob Cardiol Sci Pr. 2012;2012(1):10.

86. Hülsmann M, Quittan M, Berger R, Crevenna R, Springer C, Nuhr M, et al. Muscle strength as a predictor of long-term survival in severe congestive heart failure. Eur $\mathbf{J}$ Heart Fail. 2004;6:101-7.

87. Gutekunst DJ. Isokinetic Torque Timing Parameters and Ceramides as Markers of Muscle Dysfunction in Systolic Heart Failure. J Card Fail [Internet]. 2016; Available from: http://dx.doi.org/10.1016/j.cardfail.2016.03.018

88. Molina R, Denadai BS. Dissociated time course recovery between rate of force development and peak torque after eccentric exercise. 2012;179-84. 
89. Chiappa GR, Callegaro CC. Contribuição da musculatura inspiratória na limitação ao exercício na insuficiência cardíaca : mecanismos fisiopatológicos failure : pathophysiological mechanisms. 2012;16(4):261-7.

90. Aagaard P, Simonsen EB, Andersen JL, Magnusson P, Dyhre-Poulsen P. Increased rate of force development and neural drive of human skeletal muscle following resistance training. J Appl Physiol [Internet]. 2002 Oct [cited 2014 Jul 15];93(4):1318-26. Available from: http://www.ncbi.nlm.nih.gov/pubmed/12235031

91. Guazzi M, Adams V, Conraads V, Halle M, Mezzani A, Vanhees L, et al. EACPR/AHA Scientific Statement. Clinical recommendations for cardiopulmonary exercise testing data assessment in specific patient populations. Circulation [Internet]. 2012 Oct 30 [cited 2014 May 27];126(18):2261-74. Available from: http://www.ncbi.nlm.nih.gov/pubmed/22952317

92. Arena R, Myers J, Guazzi M. The clinical and research applications of aerobic capacity and ventilatory efficiency in heart failure: An evidence-based review. Heart Fail Rev. 2008;13(2):245-69.

93. Mancini DM, Eisen H, Kussmaul W, Mull R, Edmunds LH, Wilson JR. Value of peak exercise oxygen consumption for optimal timing of cardiac transplantation in ambulatory patients with heart failure. Circulation. 1991;83(3):778-86.

94. Co V. Teste de Exercício Cardiopulmonar. 2002;28(Supl 3):166-206.

95. Cipriano G, Cipriano VTF, Maldaner Da Silva VZ, Cipriano GFB, Chiappa GR, De Lima ACGB, et al. Aerobic exercise effect on prognostic markers for systolic heart failure patients: A systematic review and meta-analysis. Vol. 19, Heart Failure Reviews. 2014. p. 655-67.

96. Ponikowski PP, Chua TP, Francis DP, Capucci a., Coats a. JS, Piepoli MF. Muscle Ergoreceptor Overactivity Reflects Deterioration in Clinical Status and Cardiorespiratory Reflex Control in Chronic Heart Failure. Circulation. 2001 Nov;104(19):2324-30.

97. Gomes Neto M, Oliveira FA, Reis HFC dos, de Sousa Rodrigues- E, Bittencourt HS, Carvalho VO. Effects of Neuromuscular Electrical Stimulation on Physiologic and Functional Measurements in Patients With Heart Failure: A SYSTEMATIC REVIEW WITH META-ANALYSIS. J Cardiopulm Rehabil Prev [Internet]. 2016;100:1. Available from: http://content.wkhealth.com/linkback/openurl?sid=WKPTLP:landingpage \&an=012731 16-900000000-99700\%5Cnhttp://www.ncbi.nlm.nih.gov/pubmed/26784735

98. Harris S, LeMaitre JP, Mackenzie G, Fox KAA, Denvir MA. A randomised study of home-based electrical stimulation of the legs and conventional bicycle exercise training for patients with chronic heart failure. Eur Heart J. 2003;24(9):871-8.

99. Karavidas A, Parissis JT, Matzaraki V, Arapi S, Varounis C, Ikonomidis I, et al. Functional Electrical Stimulation is More Effective in Severe Symptomatic Heart Failure Patients and Improves Their Adherence to Rehabilitation Programs. J Card Fail [Internet]. 2010;16(3):244-9. Available from: http://dx.doi.org/10.1016/j.cardfail.2009.10.023

100. Della R, Plentz M, Sbruzzi G, Ribeiro RA, Ferreira JB, Lago PD. Review Article Inspiratory Muscle Training in Patients with Heart Failure : Meta- Analysis of Randomized Trials. 2012;762-71.

101. Veldman MP, Gondin J, Place N, Maffiuletti NA. Effects of Neuromuscular Electrical 
Stimulation Training on Endurance Performance. Front Physiol [Internet].

2016;7(November). Available from:

http://journal.frontiersin.org/article/10.3389/fphys.2016.00544/full

102. Nuhr MJ, Pette D, Berger R, Quittan M, Crevenna R, Huelsman M, et al. Beneficial effects of chronic low-frequency stimulation of thigh muscles in patients with advanced chronic heart failure. Eur Heart J. 2004;25(2):136-43.

103. Quittan M, Wiesinger GF, Sturm B, Puig S, Mayr W, Sochor A, et al. Improvement of Thigh Muscles by Neuromuscular Electrical Stimulation in Patients with Refractory Heart Failure. Am J Phys Med Rehabil. 2001 Mar;80(3):206-14.

104. Dobsák P, Nováková M, Siegelová J, Fiser B, Vítovec J, Nagasaka M, et al. Lowfrequency electrical stimulation increases muscle strength and improves blood supply in patients with chronic heart failure. Circ J [Internet]. $2006 \mathrm{Jan} ; 70(1): 75-82$. Available from: http://www.ncbi.nlm.nih.gov/pubmed/16377928

105. Karavidas A, Driva M, Parissis JT, Farmakis D, Mantzaraki V, Varounis C, et al. Functional electrical stimulation of peripheral muscles improves endothelial function and clinical and emotional status in heart failure patients with preserved left ventricular ejection fraction. Am Heart J [Internet]. 2013;166(4):760-7. Available from: http://dx.doi.org/10.1016/j.ahj.2013.06.021

106. Deftereos S, Giannopoulos G, Raisakis K, Kossyvakis C, Kaoukis A, Driva M, et al. Comparison of muscle functional electrical stimulation to conventional bicycle exercise on endothelium and functional status indices in patients with heart failure. Am J Cardiol [Internet]. 2010 Dec 1 [cited 2014 Sep 9];106(11):1621-5. Available from: http://www.ncbi.nlm.nih.gov/pubmed/21094364

107. Banerjee P. Electrical Muscle Stimulation for Heart Failure: where do we Stand? J Clin Exp Cardiolog [Internet]. 2013;4(2). Available from: http://www.omicsonline.org/2155-9880/2155-9880-4-e120.digital/2155-9880-4e120.html

108. Lake D a. Neuromuscular electrical stimulation. An overview and its application in the treatment of sports injuries. Sport Med. 1992;13(5):320-36.

109. Wisløff U, Støylen A, Loennechen JP, Bruvold M, Rognmo Ø, Haram PM, et al. Superior cardiovascular effect of aerobic interval training versus moderate continuous training in heart failure patients: A randomized study. Circulation. 2007;115(24):308694.

110. Parissis J, Farmakis D, Karavidas A, Arapi S, Lekakis J. Functional electrical stimulation of lower limb muscles as an alternative mode of exercise training in chronic heart failure : practical considerations and proposed algorithm. Eur J Heart Fail. 2015;17:228-30.

111. Estefânia M, Otto B, Pereira MM, Lima A, Beck DS, Milani M. Original Article Correlation between Diastolic Function and Maximal Exercise Capacity on Exercise Test. 2010;(January 2008):107-12.

112. Marqueti RC, Prestes J, Paschoal M, Ramos OHP, Perez SEA, Selistre-de-araujo HFCHS. Matrix metallopeptidase 2 activity in tendon regions : e V ects of mechanical loading exercise associated to anabolic-androgenic steroids. 2008;1087-93.

113. Mitelman AK, Buccheri V, Rubens C V, Poppe S, Cavalcante AMMP, Monteiro SM. Quantificação das citocinas séricas Th1 / Th2 por citometria de fluxo no linfoma de Hodgkin clássico. 2009;1-7. 
114. Miranda K. A Rapid, Simple Spectrophotometric Method for Simultaneous Detection of Nitrate and Nitrite. Nitric Oxide [Internet]. 2001;5(1):62-71. Available from: http://linkinghub.elsevier.com/retrieve/pii/S1089860300903197\%5Cnpapers2://publica tion/doi/10.1006/niox.2000.0319

115. Abdul-Waheed M, Yousuf M, Kelly SJ, Arena R, Ying J, Naz T, et al. Does left atrial volume affect exercise capacity of heart transplant recipients? J Cardiothorac Surg. 2010;5:113.

116. Arena R, Myers J, Aslam SS, Varughese EB, Peberdy MA. Technical Considerations Related to the Minute Ventilation/Carbon Dioxide Output Slope in Patients With Heart Failure. 2003;

117. Balady GJ, Williams M a, Ades P a, Bittner V, Comoss P, Foody JM, et al. Core components of cardiac rehabilitation/secondary prevention programs: 2007 update: a scientific statement from the American Heart Association Exercise, Cardiac Rehabilitation, and Prevention Committee, the Council on Clinical Cardiology; the Councils o. Circulation [Internet]. 2007 May 22 [cited 2014 Aug 20];115(20):2675-82. Available from: http://www.ncbi.nlm.nih.gov/pubmed/17513578

118. Biodex Medical Systems Inc. System 3 Pro Application / Operation Manual. 2015;6339:1-108. Available from: http://www.biodex.com/sites/default/files/835000man_06159.pdf

119. Carregaro R, Cunha R, Gomes C, Brown LE, Bottaro M. Muscle fatigue and metabolic responses following three different antagonist pre-load resistance exercises. J Electromyogr Kinesiol [Internet]. 2013;23(5):1090-6. Available from: http://dx.doi.org/10.1016/j.jelekin.2013.04.010

120. Hermens HJ, Freriks B, Disselhorst-Klug C, Rau G. Development of recommendations for SEMG sensors and sensor placement procedures. J Electromyogr Kinesiol. 2000;10:361-74.

121. Botter A, Oprandi G, Lanfranco F, Allasia S, Maffiuletti NA, Minetto MA. Atlas of the muscle motor points for the lower limb: Implications for electrical stimulation procedures and electrode positioning. Eur J Appl Physiol. 2011;111:2461-71.

122. AGNE J. Escala visual analógica. 2014; Available from: http://www.eletroterapia.com.br/regua_dor.jpg

123. Reihmane D, Jurka A, Tretjakovs P, Dela F. Increase in IL-6, TNF-alpha, and MMP-9, but not sICAM-1, concentrations depends on exercise duration. Eur J Appl Physiol. 2013;113(4):851-8.

124. Durigan JLQ, Peviani SM, Delfino GB, de Souza José RJ, Parra T, Salvini TF. Neuromuscular electrical stimulation induces beneficial adaptations in the extracellular matrix of quadriceps muscle after anterior cruciate ligament transection of rats. Am J Phys Med Rehabil. 2014;93(11):948-61.

125. Purslow PP. Strain-induced reorientation of an intramuscular connective tissue network: Implications for passive muscle elasticity. J Biomech. 1989;22(1):21-31.

126. Lucotti P, Monti LD, Setola E, Galluccio E, Gatti R, Bosi E, et al. Aerobic and resistance training effects compared to aerobic training alone in obese type 2 diabetic patients on diet treatment. Diabetes Res Clin Pract [Internet]. 2011;94(3):395-403. Available from: http://dx.doi.org/10.1016/j.diabres.2011.08.002

127. Peviani SM, Russo TL, Durigan JLQ, Vieira BS, Pinheiro CM, Galassi MS, et al. Stretching and electrical stimulation regulate the metalloproteinase-2 in rat denervated 
skeletal muscle. Neurol Res [Internet]. 2010;32(8):891-6. Available from: http://www.ncbi.nlm.nih.gov/pubmed/19660200

128. Bradham WS, Moe G, Wendt K a, Scott A a, Konig A, Romanova M, et al. TNF-alpha and myocardial matrix metalloproteinases in heart failure: relationship to LV remodeling. Am J Physiol Heart Circ Physiol [Internet]. 2002;282(4):H1288-95. Available from: http://www.ncbi.nlm.nih.gov/pubmed/11893563

129. Bickel CS, Gregory CM, Dean JC. Motor unit recruitment during neuromuscular electrical stimulation: A critical appraisal. Eur J Appl Physiol. 2011;111(10):2399-407.

130. Gondin J, Cozzone PJ, Bendahan D. Is high-frequency neuromuscular electrical stimulation a suitable tool for muscle performance improvement in both healthy humans and athletes? Vol. 111, European Journal of Applied Physiology. 2011. p. 2473-87.

131. Pérez M, Lucia A, Rivero JLL, Serrano AL, Calbet JAL, Delgado MA, et al. Effects of transcutaneous short-term electrical stimulation on $\mathrm{M}$. vastus lateralis characteristics of healthy young men. Pflugers Arch Eur J Physiol. 2002;443(5-6):866-74.

132. Vivodtzev I, Debigar?? R, Gagnon P, Mainguy V, Saey D, Dub?? A, et al. Functional and muscular effects of neuromuscular electrical stimulation in patients with severe COPD: A randomized clinical trial. Chest [Internet]. 2012;141(3):716-25. Available from: http://dx.doi.org/10.1378/chest.11-0839

133. Collins DF, Burke D, Gandevia SC. Sustained contractions produced by plateau-like behaviour in human motoneurones. J Physiol [Internet]. 2002;538(Pt 1):289-301. Available from: papers://5a68cd75-9e27-4626-8d94057f1df96060/Paper/p1934\%5Cnhttp://www.ncbi.nlm.nih.gov/pubmed/11773336\%5C nhttp://www.pubmedcentral.nih.gov/articlerender.fcgi?artid=PMC2290016

134. Montera V. Benefícios dos Nutrientes Antioxidantes e seus Cofatores no Controle do Estresse Oxidativo e Inflamação na Insuficiência Cardíaca. 2007;20:20-7.

135. Weant KA, Smith KM. The role of coenzyme Q10 in heart failure. Ann Pharmacother. 2005;39(9):1522-6.

136. Thériault R, Thériault G, Simoneau J a. Human skeletal muscle adaptation in response to chronic low-frequency electrical stimulation. J Appl Physiol. 1994;77(4):1885-9.

137. Giordano FJ. Oxygen, oxidative stress, hypoxia, and heart failure. J Clin Invest. 2005;115(3):500-8.

138. Banerjee P, Caulfield B, Crowe L, Clark AL. Prolonged electrical muscle stimulation exercise improves strength, peak VO2, and exercise capacity in patients with stable chronic heart failure. J Card Fail [Internet]. 2009 May [cited 2014 Sep 7];15(4):31926. Available from: http://www.ncbi.nlm.nih.gov/pubmed/19398080

139. Deley G, Kervio G, Verges B, Hannequin a., Petitdant M-F, Salmi-Belmihoub S, et al. Comparison of low-frequency electrical myostimulation and conventional aerobic exercise training in patients with chronic heart failure. Eur J Cardiovasc Prev Rehabil. 2005 Jun;12(3):226-33.

140. LeMaitre JP, Harris S, Hannan J, Fox KAA, Denvir MA. Maximum oxygen uptake corrected for skeletal muscle mass accurately predicts functional improvements following exercise training in chronic heart failure. Eur J Heart Fail [Internet]. 2006;8(3):243-8. Available from: https://www.scopus.com/inward/record.url?eid=2s2.0-33646371706\&partnerID $=40 \& \mathrm{md} 5=65 \mathrm{ab} 477 \mathrm{bd} 9814 \mathrm{f} 33848 \mathrm{~cd} 3 \mathrm{e} 117 \mathrm{de} 5 \mathrm{ea} 0$ 
141. Danneskiold-Samsøe B, Bartels EM, Bülow PM, Lund H, Stockmarr A, Holm CC, et al. Isokinetic and isometric muscle strength in a healthy population with special reference to age and gender. Acta Physiol. 2009;197(SUPPL. 673):1-68.

142. Maffiuletti NA, Aagaard P, Blazevich AJ, Folland J, Tillin N, Duchateau J. Rate of force development: physiological and methodological considerations. Eur J Appl Physiol. 2016;116(6):1091-116.

143. de Ruiter CJ, Kooistra RD, Paalman MI, de Haan A. Initial phase of maximal voluntary and electrically stimulated knee extension torque development at different knee angles. J Appl Physiol [Internet]. 2004;97(5):1693-701. Available from: http://jap.physiology.org/content/97/5/1693.abstract

144. Maffiuletti NA. Physiological and methodological considerations for the use of neuromuscular electrical stimulation. Eur J Appl Physiol. 2010;110(2):223-34.

145. Deley G, Babault N. Could low-frequency electromyostimulation training be an effective alternative to endurance training? An overview in one adult. J Sport Sci Med. 2014;13(2):444-50. 


\section{APÊNDICE A - Termo de Consentimento Livre e Esclarecido}

Convidamos o(a) Senhor(a) a participar voluntariamente do projeto de pesquisa "Efeitos da estimulação elétrica de baixa frequência no remodelamento e desempenho muscular, resposta oxidativa e inflamatória em pacientes com insuficiência cardíaca", sob a responsabilidade do pesquisador Marianne Lucena da Silva. O projeto será destinado a avaliar os efeitos fisiológicos e funcionais da aplicação de eletroestimulação de baixa frequência na musculatura de membros inferiores em pacientes com insuficiência cardíaca que estão na fila de espera para fisioterapia e/ou não tem acesso nenhum tipo de atividade física.

O objetivo desta pesquisa é avaliar os efeitos de um programa domiciliar de dez semanas com estimulação elétrica, em pacientes com Insuficiência Cardíaca.

$\mathrm{O}$ (a) senhor(a) receberá todos os esclarecimentos necessários antes e no decorrer da pesquisa e lhe asseguramos que seu nome não aparecerá sendo mantido o mais rigoroso sigilo pela omissão total de quaisquer informações que permitam identificá-lo(a).

A sua participação se dará por meio de avaliações com Ecocardiograma, teste cardiopulmonar, exame de sangue e avaliação de força muscular esquelética, que será realizado no Instituto de Cardiologia do Distrito Federal, No Hospital das Forças Armadas e na Faculdade de Educação Física da Universidade de Brasília em antes e imediatamente após as dez semanas de uso de equipamento portal de eletroestimulação com um tempo estimado de cada procedimento de 30 minutos a 1 hora e o total de seis visitas para sua realização.

A coleta não apresentará riscos aos indivíduos com Insuficiência Cardíaca, uma vez que eles serão acompanhados por um médico em todas as avaliações tanto de ergoespirometria quanto no isocinético. Para coleta de sangue, foi assegurada utilização de agulhas descartáveis e que as coletas são pouco invasivas e serão realizadas por profissional competente, utilizados todos os cuidados e proteção necessários, exigidos pela Agencia Nacional de Vigilância Sanitária. Se você aceitar participar, estará contribuindo para a compreensão do uso da eletroestimulação no tratamento de pacientes com insuficiência cardíaca.

$\mathrm{O}$ (a) Senhor(a) pode se recusar a responder (ou participar de qualquer procedimento) qualquer questão que lhe traga constrangimento, podendo desistir de participar da pesquisa em qualquer momento sem nenhum prejuízo para o(a) senhor(a). Sua participação é voluntária, isto é, não há pagamento por sua colaboração.

Todas as despesas que você tiver relacionadas diretamente ao projeto de pesquisa (tais como, passagem para o local da pesquisa, alimentação no local da pesquisa ou exames para realização da pesquisa) serão cobertas pelo pesquisador responsável.

Caso haja algum dano direto ou indireto decorrente de sua participação na pesquisa, você deverá buscar ser indenizado, obedecendo-se as disposições legais vigentes no Brasil.

Os resultados da pesquisa serão divulgados na Universidade de Brasília - UnB, podendo ser publicados posteriormente. Os dados e materiais serão utilizados somente para esta pesquisa e ficarão sob a guarda do pesquisador por um período de cinco anos, após isso serão destruídos.

Se o(a) Senhor(a) tiver qualquer dúvida em relação à pesquisa, por favor telefone para: Marianne Lucena da Silva, na Universidade de Brasília- Faculdade de Ceilândia, no telefone (061) 84973989 ou (61) 33877471, e-mail: mariannebsb@gmail.com, disponível inclusive para ligação a cobrar.

Este projeto foi aprovado pelo Comitê de Ética em Pesquisa da Faculdade de Ciências da Saúde (CEP/FS) da Universidade de Brasília. O CEP é composto por profissionais de diferentes áreas cuja função é defender os interesses dos participantes da pesquisa em sua integridade e dignidade e contribuir no desenvolvimento da pesquisa dentro de padrões éticos. As dúvidas com relação à assinatura do TCLE ou os direitos do participante da pesquisa podem ser esclarecidos pelo telefone (61) 3107-1947 ou do e-mail cepfs@ unb.br ou cepfsunb@gmail.com, horário de atendimento de 10:00hs às 12:00hs e de 13:30hs às 15:30hs, de segunda a sextafeira. O CEP/FS se localiza na Faculdade de Ciências da Saúde, Campus Universitário Darcy Ribeiro, Universidade de Brasília, Asa Norte.

Caso concorde em participar, pedimos que assine este documento que foi elaborado em duas vias, uma ficará com o pesquisador responsável e a outra com o Senhor (a).

Nome / assinatura

Pesquisador Responsável

Nome e assinatura

Brasília, de de 


\section{APÊNDICE B - Ficha de Identificação da Amostra}

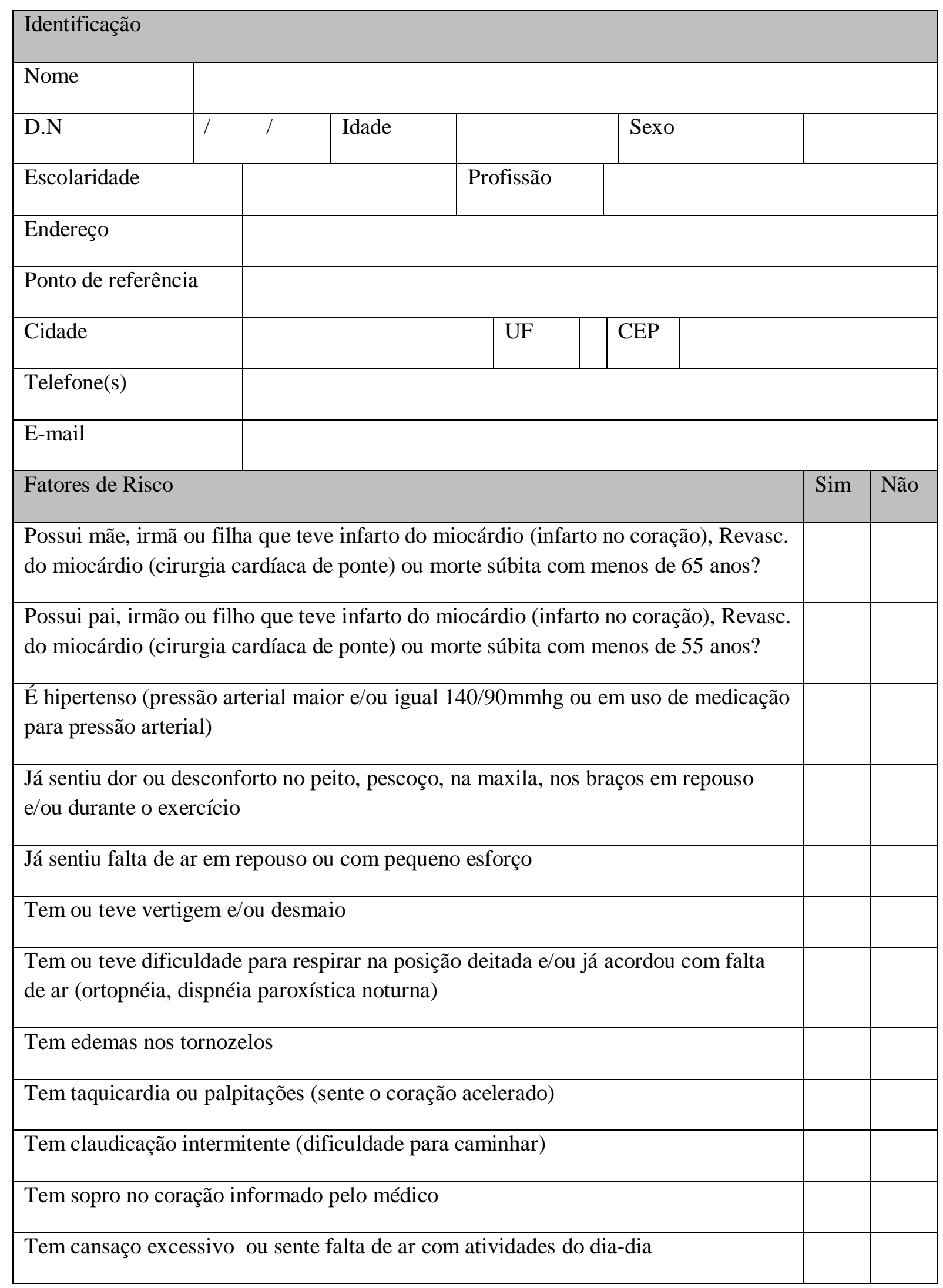




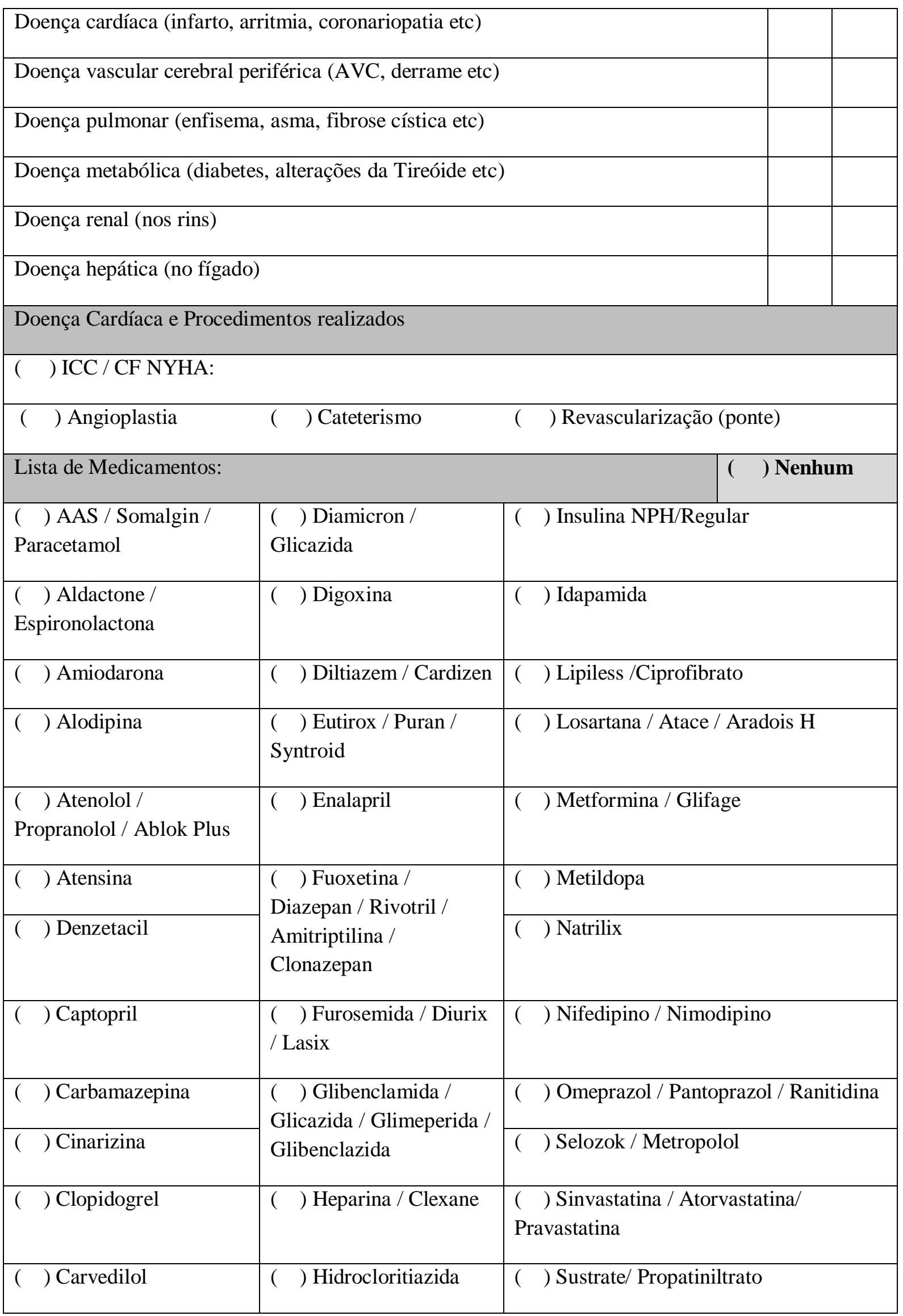




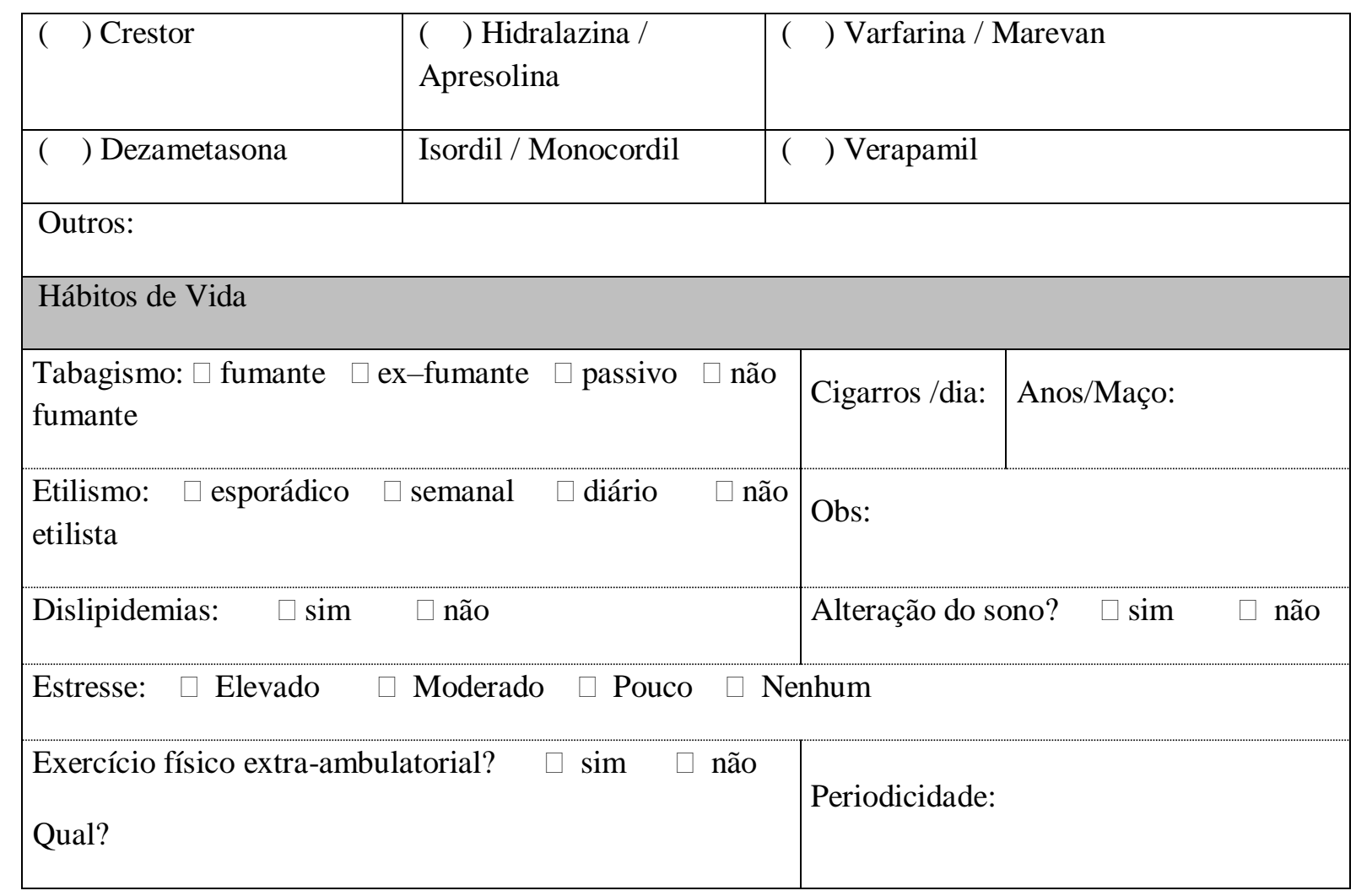




\section{APÊNDICE C - Contribuições Científicas durante o Doutorado}

Período: Agosto de 2013 a Novembro de 2016

Artigos submetidos:

- Autor principal: Classificação Internacional da Funcionalidade em pacientes com insuficiência cardíaca isquêmica: Um estudo Transversal; Revista Fisioterapia e Pesquisa; Artigos Aprovados:

- Coautor: Maximal Inspiratory Pressure: Does the Choice of Reference Values Actually Matter?. CHEST Journal, dezembro de 2016

- Coautor: "Oral $\mathrm{N}$-acetylcysteine and exercise tolerance in mild chronic obstructive pulmonary disease", Journal of Applied Physiology, janeiro de 2017.

Resumos:

- Maximal inspiratory pressure: does the choice of reference values matter?, coautor, European Respiratory Society 2016 International Congress (London, UK);

- Acute Effects of Interferential Electrical Stimulation of Heart Rate Variability in Healthy Women, coautor, American Association of Cardiovascular e Pulmonary Rehabilitation $30^{\text {th }}$, Annual Meeting Scientific Abstracts, At Washington - DC, Volume: 35 ;

- Five Week Daily Neuromuscular Electrical Stimulation (NMES) Can be Exhaustive for End Stage Heart Failure (HF) patients, autor, American Association of Cardiovascular e Pulmonary Rehabilitation $30^{\text {th }}$, Annual Meeting Scientific Abstracts, At Washington - DC, Volume: 35. 


\section{ANEXO A - Termo de Aprovação do Comitê de Ética e Pesquisa}

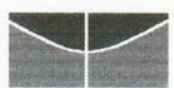

Universidade de Brasília

Faculdade de Ciências da Saúde

Comitê de Ética em Pesquisa - CEP/FS

\section{PROCESSO DE ANÁLISE DE PROJETO DE PESQUISA}

Registro do Projeto no CEP: 115/10

Título do Projeto: "Uso de Biotecnologia em Insuficiência Cardíaca: Os efeitos de Cinco semanas de Mioestimulação Elétrica".

Pesquisador Responsável: Marianne Lucena da Silva

Data da Entrada: 13/09/10

Com base na Resolução 196/96, do CNS/MS, que regulamenta a ética em pesquisa com seres humanos, o Comitê de Ética em Pesquisa com Seres Humanos da Faculdade de Ciências da Saúde da Universidade de Brasília, após análise dos aspectos éticos e do contexto técnico-científico, resolveu APROVAR o projeto 115/10 com o título: "Uso de Biotecnologia em Insuficiência Cardíaca: Os efeitos de Cinco semanas de Mioestimulação Elétrica", analisado na $12^{\mathrm{a}}$ Reunião Ordinária, realizada no dia 14 de dezembro de 2010.

A pesquisadora responsável fica, desde já, notificada da obrigatoriedade da apresentação de um relatório semestral e relatório final sucinto e objetivo sobre o desenvolvimento do Projeto, no prazo de 1 (um) ano a contar da presente data (item VII.13 da Resoluçăo 196/96).

Brasília, 02 de junho de 2011.

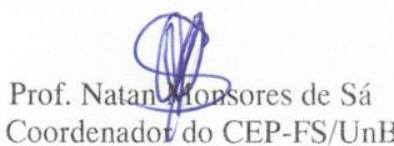

Coordenadot do CEP-FS/UnB

Comitê de Ética em Pesquisa com Seres Humanos - Faculdade de Ciências da Saúde 